\title{
Role of Ural blocking in Arctic sea ice loss and its connection with Arctic warming in winter
}

\author{
Dong-Jae Cho ${ }^{1} \cdot$ Kwang-Yul Kim $^{1}$ (1)
}

Received: 13 July 2020 / Accepted: 17 November 2020 / Published online: 5 December 2020

(C) The Author(s) 2020

\begin{abstract}
Ural blocking (UB) is suggested as one of the contributors to winter sea ice loss in the Barents-Kara Seas (BKS). This study compares UB with Arctic warming (AW) in order to delineate the role of UB on winter sea ice loss and its potential link with AW. A detailed comparison reveals that UB and AW are partly linked on sub-seasonal scales via a two-way interaction; circulation produced by AW affects UB and advection induced by UB affects temperature in AW. On the other hand, the long-term impacts of AW and UB on the sea ice concentration in the BKS are distinct. In AW, strong turbulent flux from the sea surface warms the lower troposphere, increases downward longwave radiation, and broadens the open sea surface. This feedback process explains the substantial sea ice reduction observed in the BKS in association with long-term accelerating trend. Patterns of turbulent flux, net evaporation, and net longwave radiation at surface associated with UB are of opposite signs to those associated with AW, which implies that moisture and heat flux is suppressed as warm and moist air is advected from mid-latitudes. As a result, vertical feedback process is hindered under UB. The qualitative and quantitative differences arise in terms of their impacts on sea ice concentrations in the BKS, because strong turbulent flux from the open sea surface is a main driving force in AW whereas heat and moisture advection is a main forcing in UB.
\end{abstract}

Keywords Sea ice concentration · Ural blocking $\cdot$ Arctic warming $\cdot$ Feedback mechanism $\cdot$ Heat and moisture budget analysis

\section{Introduction}

Growing concerns over the recent changes of rapid sea ice loss and atmospheric warming in the Arctic, known as Arctic warming (AW), have led to major debates on its linkage to mid-latitude weather in winter (Cohen et al. 2020). A number of studies suggested a connection between AW and harsh mid-latitude winters, which is often referred as "warm Arctic-cold Eurasia (WACE)" (Overland et al. 2011; Francis and Vavrus 2012; Mori et al. 2014; Kug et al. 2015). Meanwhile, other studies report that recent WACE is associated with natural variability rather than AW (Singarayer

Electronic supplementary material The online version of this article (https://doi.org/10.1007/s00382-020-05545-3) contains supplementary material, which is available to authorized users.

Kwang-Yul Kim

kwang56@snu.ac.kr

1 School of Earth and Environmental Sciences, Seoul National University, Seoul 08826, Republic of Korea et al. 2005; Barnes 2013; Blackport and Screen 2020; Dai and Song 2020). Screen (2017) showed that atmospheric response to a regional forcing (sea ice reduction) resembles the WACE pattern, although an ensemble of model simulations with a pan-Arctic forcing did not yield mid-latitude cooling. This shows that observational and modeling studies are in accord only on a regional scale (see Fig. 3 in Cohen et al. 2020).

Despite that the connection between AW and WACE is inconclusive, a consensus has been reached on a rapid sea ice loss and its importance on Arctic climate change (Screen and Simmonds 2010; Stroeve et al. 2011; Cohen et al. 2014). In particular, significant winter sea ice loss in the Barents-Kara Seas (BKS) drew a strong attention, due to its distinctive nature compared with other regions in the Arctic (Petoukhov and Semenov 2010; Comiso 2012; Kim et al. 2016). Several mechanisms have been suggested for winter sea ice loss, including meridional transports of heat (Graversen et al. 2008; Screen et al. 2012) and moisture (Park et al. 2015), increased cloud cover (Francis and Hunter 2006), and the temperature feedbacks including 
lapse-rate feedback and Planck feedback leading to surface warming in the Arctic (Pithan and Mauritsen 2014). The "insulation feedback" is recognized as one of the fundamental mechanisms for winter sea ice loss. Sea ice retreat exposes the open sea surface and turbulent heat flux is released into the air, accelerating the lower troposphere warming (Serreze et al. 2009; Deser et al. 2010; Screen et al. 2014; Kim et al. 2016, 2019).

Earlier studies suggested that the recent extreme sea ice loss in the BKS in winter is associated with Ural blocking (UB). Gong and Luo (2017) reported that UB leads sea ice loss in the BKS by 4 days, accompanying moisture flux convergence and downward longwave radiation (LW) anomalies. Chen et al (2018) suggested that the cases of quasi-stationary UB events, a main factor for sea ice reduction via increased downward LW, have increased in the recent 2 decades. Tyrlis et al (2019) analyzed the impact of UB on the sea ice loss in the BKS in 2016-2017, showing that anomalous $2 \mathrm{~m}$ air temperature is related to warm and moist advection during UB events. Peings (2019) showed that imposing the UB pattern in November yields the WACE pattern with sea ice anomalies in the BKS.

However, it is still unclear how UB events influence sea ice loss in the BKS quantitatively on multi-decadal scales. In addition, relative contributions of anomalous moisture and temperature from large-scale atmospheric circulation (remote) and atmosphere-ocean surface interaction (local) processes are not well understood in association with UB. Moreover, whether UB has any connections to AW needs to be investigated. The mechanism of sea ice reduction associated with UB needs to be revisited, in order to clarify whether it has discernible characteristics compared with the AW.

The purpose of this study is to assess the impact of UB on winter sea ice loss in the BKS during 1979-2018 and the characteristics of their interactions both qualitatively and quantitatively. To extract the characteristic features of UB, anomalies of variables are projected on the UB index, which hereafter is called the "UB mode". The UB mode will be compared with the sea ice loss mode (Kim et al. 2019; Kim and Kim 2019) obtained via cyclostationary empirical orthogonal function (CSEOF) analysis to investigate how they are connected with each other. In Sect. 2, information on the employed datasets, and the method of analysis will be discussed including a detailed description of the moisture and heat budget analysis. As an extension of the previous study (Kim and Kim 2019), moisture and thermal energy budget for the UB mode will be investigated in Sect. 3.1. They will be compared to the sea ice loss (hereafter AW) mode in Sect. 3.2. Then, a possible link between the UB and the AW modes will be discussed in Sect. 3.3. Characteristics of sea ice reduction associated with the two modes will be examined in Sect. 3.4, followed by concluding remarks in Sect. 4.

\section{Data and method of analysis}

\subsection{Data}

ERA-interim $1.5^{\circ} \times 1.5^{\circ}$ daily datasets from 1979 to 2018 are used for this study (Dee et al. 2011). Both pressure level variables including air temperature, geopotential, horizontal wind, vertical (pressure) velocity, and specific humidity and surface variables including sea ice concentration, surface $(2 \mathrm{~m})$ air temperature, evaporation, precipitation, latent heat, sensible heat, net longwave radiation at surface and top of the atmosphere are analyzed over the winter days (Dec. 1-Feb. 28; 90 days). The scope of analysis is limited to the Arctic region $\left(60^{\circ}-87^{\circ} \mathrm{N}\right)$.

\subsection{CSEOF analysis}

Cyclostationary empirical orthogonal function (CSEOF) analysis (Kim et al. 1996, 2015; Kim and North 1997) decompose space-time data as

$T(r, t)=\sum_{n} B_{n}(r, t) T_{n}(t), \quad t=1, \ldots, N, \quad r=1, \ldots, K$,

where $B_{n}(r, t)$ are cyclostationary loading vectors (CSLV) and $T_{n}(t)$ are corresponding principal (PC) time series. Each CSLV is a periodic function and represents temporally evolving signal over a period $d$, called the nested period. The corresponding PC time series represents the amplitude of the CSLV. CSLVs are mutually orthogonal and PC time series are uncorrelated with each other, i.e.,

$\frac{1}{K d} \sum_{t=1}^{d} \sum_{r=1}^{K} B_{n}(r, t) B_{m}(r, t)=\lambda_{n} \delta_{n m}$,

$\frac{1}{N} \sum_{t=1}^{N} T_{n}(t) T_{m}(t)=\delta_{n m}$

where $\delta_{n m}$ is the Kronecker delta. Thus, CSEOF analysis decomposes data into mutually orthogonal evolutions within the period $d$ with their amplitude time series uncorrelated with each other.

When CSEOF analysis is conducted on many variables, physical consistency among different variables should be ensured. For example, another variable is decomposed as

$P(r, t)=\sum_{n} C_{n}(r, t) P_{n}(t), \quad t=1, \ldots, N, \quad r=1, \ldots, K$, 
where $C_{n}(r, t)$ are CSLVs and $P_{n}(t)$ PC time series of the new variable. Since $T_{n}(t) \neq P_{n}(t)$, in general, the two sets of CSLVs, $B_{n}(r, t)$ and $C_{n}(r, t)$, are not physically consistent. In order to make the two sets of CSLVs physically consistent with each other, regression analysis is carried out in CSEOF space:

$T_{n}(t)=\sum_{m=1}^{M} \alpha_{m}^{(n)} P_{m}(t)+\epsilon(t), \quad t=1, \ldots, N$,

$C_{n}^{(\mathrm{reg})}(r, t)=\sum_{m=1}^{M} \alpha_{m}^{(n)} C_{m}(r, t), \quad t=1, \ldots, d, \quad r=1, \ldots, K$,

where $\alpha_{m}^{(n)}$ are regression coefficients, $\epsilon(t)$ is regression error time series, and $M(=20$ in the present study) is the number of PC time series used for regression. Then the first (target) variable and the second (predictor) variable can be written together as $\frac{\partial q}{\partial t}=-\vec{V} \cdot \nabla_{p} q-\omega \frac{\partial q}{\partial p}+S$

where $q$ is specific humidity, $\vec{V}$ horizontal velocity, $p$ pressure, $\omega$ vertical (pressure) velocity, and $S$ for moisture source (sink) rate. Subscript $p$ with the $\nabla$ operator denotes differentiation on isobaric surfaces. Equation (8) is rewritten into a flux form by applying the continuity equation in pressure coordinate:

$\frac{\partial q}{\partial t}=-\nabla_{p} \cdot(q \vec{V})-\frac{\partial(q \omega)}{\partial p}+S$.

Multiplying air density and vertically integrating from the surface $\left(z_{s}\right)$ to the top of the atmosphere $\left(z_{t}\right)$ leads to

$\int_{z_{s}}^{z_{t}} \rho_{a} \frac{\partial q}{\partial t} d z=-\int_{z_{s}}^{z_{t}} \rho_{a} \nabla_{p} \cdot(q \vec{V}) d z-\int_{z_{s}}^{z_{t}} \rho_{a} \frac{\partial(q \omega)}{\partial p} d z+\rho_{w}(E-P)$,

where $\rho_{a}$ and $\rho_{w}$ are the density of air and water, and $E$ and

$\{T(r, t), P(r, t)\}=\sum_{n}\left\{B_{n}(r, t), C_{n}^{(\mathrm{reg})}(r, t)\right\} T_{n}(t), \quad t=1, \ldots, N, \quad r=1, \ldots, K$.

The two sets of CSLVs are now governed by the same PC time series, and the "regressed" CSLV of the predictor variable, $C_{n}^{(\text {reg })}(r, t)$, are now considered physically consistent with the CSLV of the target variable, $B_{n}(r, t)$. This procedure can be repeated for as many predictor variables as needed.

\subsection{Ural blocking index}

A number of blocking detection algorithms have been suggested (Woollings et al. 2018). In this study, the algorithm used in Tibaldi and Molteni (1990) and Cheung and Zhou (2015) is applied to the 500-hPa geopotential height field to extract the blocking index (see also supplementary Fig. S1
$P$ are the rate of evaporation and precipitation. Multiplying both sides by gravitational constant $(g)$ with the aid of hydrostatic equation yields

$\int_{p_{t}}^{p_{s}} \frac{\partial q}{\partial t} d p=-\int_{p_{t}}^{p_{s}} \nabla_{p} \cdot(q \vec{V}) d p-\int_{p_{t}}^{p_{s}} \frac{\partial(q \omega)}{\partial p} d p+\rho_{w} g(E-P)$,

where $p_{s}$ and $p_{t}$ are the pressure at level $z_{s}$ and $z_{t}$, respectively. Note that the left-hand side of (11) can be rewritten as:

$\int_{p_{t}}^{p_{s}} \frac{\partial q}{\partial t} d p=\frac{\partial}{\partial t} \int_{p_{t}}^{p_{s}} q d p-\left[q_{s} \frac{\partial p_{s}}{\partial t}-q_{t} \frac{\partial p_{t}}{\partial t}\right]$.

Likewise, terms on the right-hand side of (11) are expressed as

$\int_{p_{t}}^{p_{s}} \nabla_{p} \cdot(q \vec{V}) d p=\nabla_{p} \cdot \int_{p_{t}}^{p_{s}}(q \vec{V}) d p-\left[\left(q_{s} \vec{V}_{s}\right) \cdot \nabla_{p} p_{s}-\left(q_{t} \vec{V}_{t}\right) \cdot \nabla_{p} p_{t}\right]$,

and the discussion therein). The index is then projected onto individual variables to obtain the Ural blocking (UB) mode.

\subsection{Moisture and thermal energy budget analysis}

Moisture conservation equation in pressure coordinate is expressed as and

$$
\int_{p_{t}}^{p_{s}} \frac{\partial(q \omega)}{\partial p} d p=q_{s}\left[\frac{\partial p_{s}}{\partial t}+\vec{V}_{s} \cdot \nabla_{p} p_{s}\right]-q_{t}\left[\frac{\partial p_{t}}{\partial t}+\vec{V}_{t} \cdot \nabla_{p} p_{t}\right] .
$$

Consequently, moisture budget equation used in the present study is 
$\frac{\partial}{\partial t} \int_{p_{t}}^{p_{s}} q d p=-\nabla_{p} \cdot \int_{p_{t}}^{p_{s}}(q \vec{V}) d p+\rho_{w} g(E-P)$.

The left-hand side of (15) represents the tendency of vertically integrated moisture between $p_{s}$ and $p_{t}$. Terms on the right are moisture flux convergence and moisture source rate. For daily analysis, (15) can be expressed as

$\Delta \int_{p_{t}}^{p_{s}} q d p=\left[-\nabla_{p} \cdot \int_{p_{t}}^{p_{s}}(q \vec{V}) d p+\rho_{w} g(E-P)\right](\Delta t)$,

where $\Delta t$ is 1 day in this study. Then, all terms in (16) are averages over 1 day. Thus, moisture budget analysis via (16) enables us to assess the relative contributions to anomalous moisture via remote process (moisture flux convergence), and local process (evaporation minus precipitation). Dividing by $\left(p_{s}-p_{t}\right),(16)$ is in unit of $\mathrm{g} \mathrm{kg}^{-1}$ so that all terms denote daily-scale variation of specific humidity.

Thermal energy equation in pressure coordinate is expressed as

$\frac{\partial T}{\partial t}=-\vec{V} \cdot \nabla_{p} T+S_{p} \omega+\frac{J}{c_{p}}$,

where $T$ is air temperature, $S_{p}$ is the stability parameter defined as

$S_{p} \equiv \frac{R T}{c_{p} p}-\frac{\partial T}{\partial p}=-\frac{T}{\theta} \frac{\partial \theta}{\partial p}$.

Here, $R$ is the specific gas constant, $c_{p}$ specific heat at constant pressure, $\theta$ potential temperature, and $J$ is heating rate per unit mass due to radiation, conduction, and latent heat release. As above, thermal energy budget equation can be expressed as

$\frac{\partial}{\partial t} \int_{p_{t}}^{p_{s}} T d p=-\int_{p_{t}}^{p_{s}} \vec{V} \cdot \nabla_{p} T d p+\int_{p_{t}}^{p_{s}} S_{p} \omega d p+\left(\frac{g}{c_{p}}\right) \int_{p_{t}}^{p_{s}} J d p$.

The last term on the right of (19) represents exchange of sensible heat, latent heat and longwave radiation flux between the atmosphere and surface. Shortwave radiation is excluded in lieu of seasonal and latitudinal considerations. Thus,

$\int_{p_{t}}^{p_{s}} J d p=F_{S}+F_{L}+F_{L W}=F_{S}+F_{L}+F_{L W S}(\uparrow)-F_{L W T}(\uparrow)$,

where $F_{L W S}$ and $F_{L W T}$ are net longwave radiation flux at the surface and the top of the atmospheric column with arrows denoting directions of flux. The ERA-interim reanalysis products provide radiation only at the surface and top of the atmosphere. Since there is a substantial correlation between the specific humidity and longwave radiation trapped in the atmosphere (see supplementary Fig. S2 and discussion therein), it is assumed that the radiative flux trapped in the lower troposphere is proportional to the ratio of specific humidity in the lower troposphere to that in the entire atmospheric column (see also Kim and Kim 2019). Note that this is an important caveat in this study. Like the moisture budget equation, (19) is expressed as:

$\Delta \int_{p_{t}}^{p_{s}} T d p=\left[-\int_{p_{t}}^{p_{s}} \vec{V} \cdot \nabla_{p} T d p+\int_{p_{t}}^{p_{s}} S_{p} \omega d p+\left(\frac{g}{c_{p}}\right) \int_{p_{t}}^{p_{s}} J d p\right](\Delta t)$.

By dividing by $\left(p_{s}-p_{t}\right)$, unit of (21) is converted into $\mathrm{K}$ so that all the budget terms denote daily-scale variation of temperature. Note that all terms in (21) are averages over 1 day. In this way, (21) enables us to analyze anomalous temperature in terms of thermal advection (remote process) and thermal energy fluxes (local process).

\section{Results and discussion}

\subsection{Patterns associated with Ural blocking}

Figure 1 shows the winter average patterns associated with Ural blocking (UB) based on the 40-year (1979-2018) record. Anomalous southerlies develop along the west side of the anomalous high transporting air from mid-latitudes to the Barents-Kara Seas (BKS) (Fig. 1b, c). Positive cores of anomalous air temperature and specific humidity are located above the region of sea ice loss (Fig. 1a). Note that these patterns resemble the surface air temperature and $500-\mathrm{hPa}$ geopotential height patterns at the mature stage of UB presented in Gong and Luo (2017; Fig. 4a, b therein). Anomalies shown in the vertical cross-sections (Fig. 1c, d) are concentrated in the lower troposphere $(1000-850 \mathrm{hPa})$. It should be noted that qualitatively identical results are obtained when the upper bound of integration is changed to $700 \mathrm{hPa}$.

To understand the anomalous moisture pattern in Fig. 1a, moisture budget analysis is conducted and results are summarized in Fig. 2. The winter-averaged patterns (Fig. 2a-d) as well as daily fluctuations of the terms in the moisture budget equation (Fig. 2e) over the region of intense sea ice loss (boxed region in Fig. 2d) are presented. Convergence of anomalous moisture flux is seen over the BKS (Fig. 2b), and is positively correlated $(+0.70)$ with specific humidity (blue, Fig. 2f) over the region of sea ice loss. This shows that moisture flux convergence explains a large fraction of variability in anomalous specific humidity (Fig. 2a). Meanwhile, evaporation minus precipitation (E-P, Fig. 2c) exhibits a pattern of opposite sign to Fig. 2b. Since evaporation depends critically on the difference of specific humidity 
(a) AIR T \& SH $\left(0.02 \mathrm{~g} \mathrm{~kg}^{-1}\right)$

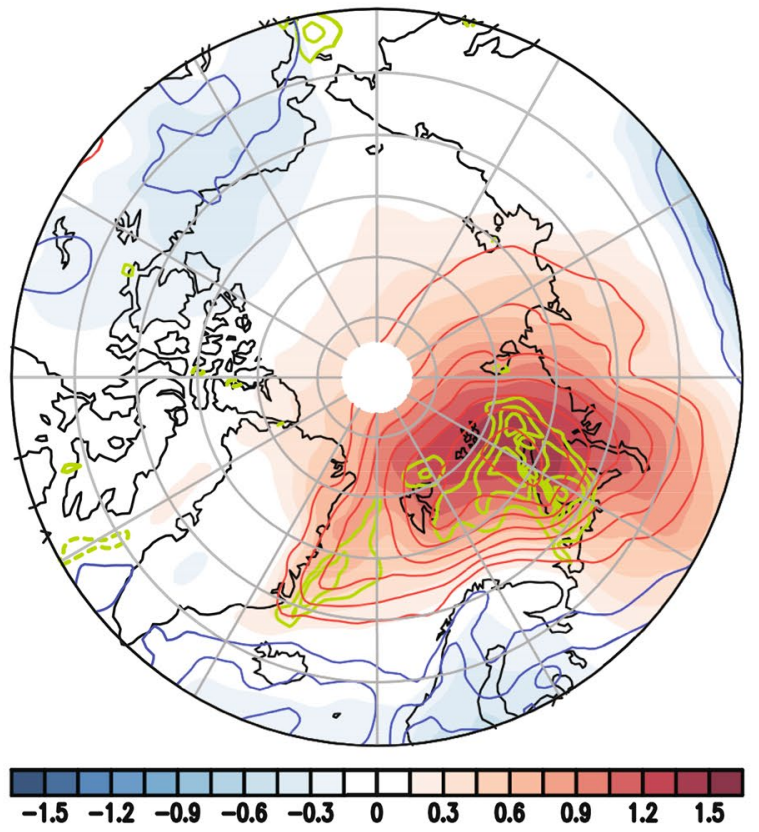

(b) GPH \& (U,V)

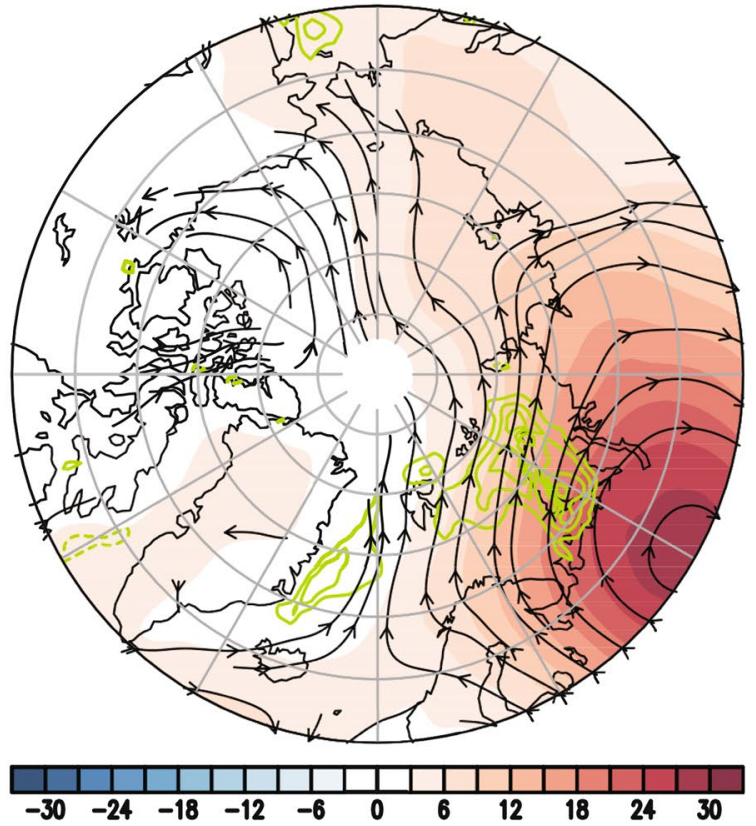

(d) $60^{\circ} \mathrm{E}$

$\mathrm{T}, \mathrm{SH} \& \mathrm{U}$

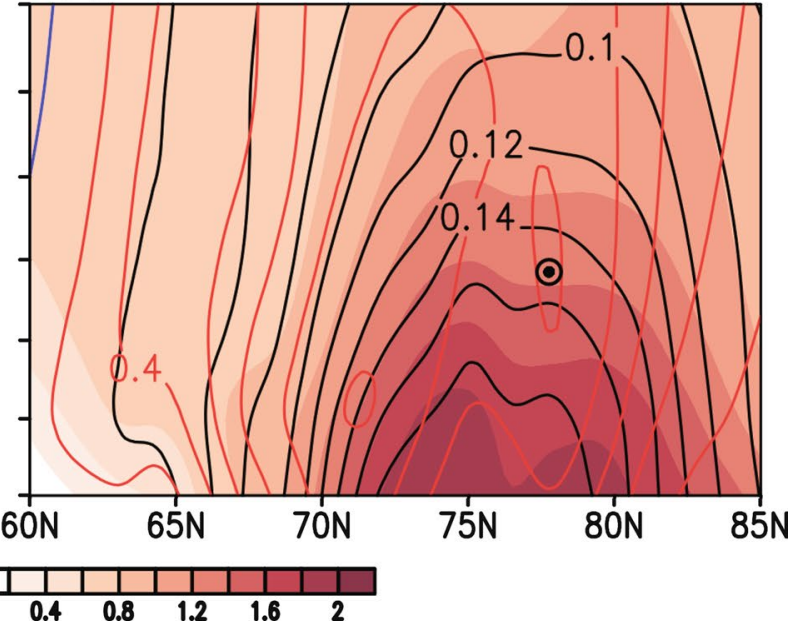

Fig. 1 Winter (DJF) averaged patterns in the lower troposphere $(1000-850 \mathrm{hPa})$ over $\left(60^{\circ}-87^{\circ} \mathrm{N}\right)$ associated with Ural blocking: a air temperature (shading, $0.15 \mathrm{~K}$ interval), specific humidity (blue $<0<$ red contours at $0.02 \mathrm{~g} \mathrm{~kg}^{-1}$ interval), sea ice concentration loss (green contour, 2\%), b geopotential height (shading, $3 \mathrm{~m}$ ) and horizontal wind, $\mathbf{c}$ vertical cross-section of air temperature (shading,

between the surface and the atmosphere above (Friehe and Schmitt 1976), the increased moisture flux convergence over the BKS implies a weakening of evaporation. Likewise, due to the linkage between moisture convergence in the lower troposphere and convective overturning over the oceans, increased precipitation is triggered by anomalous moisture flux convergence. As a result, E-P is negatively correlated $(-0.77)$ with the moisture convergence (black,
$0.2 \mathrm{~K}$ ), specific humidity (black contour, $0.02 \mathrm{~g} \mathrm{~kg}^{-1}$ ) and meridional wind (blue $<0<$ red contours, $\left.0.1 \mathrm{~m} \mathrm{~s}^{-1}\right)$ along $\left(0^{\circ}-120^{\circ} \mathrm{E}, 78^{\circ} \mathrm{N}\right)$, and $\mathbf{d}$ zonal wind (blue $<0<$ red contours, $\left.0.2 \mathrm{~m} \mathrm{~s}^{-1}\right)$ along $\left(60^{\circ} \mathrm{E}\right.$, $\left.60^{\circ}-85^{\circ} \mathrm{N}\right)$. Ural blocking index is normalized so that the patterns represent the typical (at a $1 \sigma$ level) magnitudes during a blocking event

Fig. 2f). The net moisture source, E-P, is also negatively correlated $(-0.65)$ with the specific humidity (red, Fig. 2f), justifying that increased moisture stimulates precipitation and suppresses evaporation.

During UB events, moisture flux convergence $(\mathrm{CNV})$, on average, increases winter-mean specific humidity by +0.078 $\mathrm{g} \mathrm{kg}^{-1}$, explaining $+60.9 \%$ of moisture $(\mathrm{SH})$ increase in the lower (1000-850 hPa) troposphere. On the contrary, E-P 
Fig. 2 Moisture budget in winter (DJF) in the lower troposphere (1000-850 hPa) associated with Ural blocking: a specific humidity ( $\mathrm{SH}$ ), b moisture flux convergence (CNV), c evaporation minus precipitation (E-P), $\mathbf{d}$ sum (TOT) of $\mathbf{b}$ and c. Unit in $\mathbf{a}-\mathbf{d}$ is $\mathrm{g} \mathrm{kg}^{-1}$. e Daily variation of each variable with a straight line denoting its winter mean. f Lagged correlations between the variables in e. Variables in $\mathbf{e}$ and $\mathbf{f}$ are area averages over the region $\left(21^{\circ}-79.5^{\circ}\right.$ E, $75^{\circ}-79.5^{\circ} \mathrm{N}$ ) (black box in d). Each variables' winter mean shown in $\mathbf{e}$ is the average of the 90 daily values in the time series. In $\mathbf{f}$, the first variable leads the second variable for a positive lag. Patterns over the dotted areas are significant at a $90 \%$ level
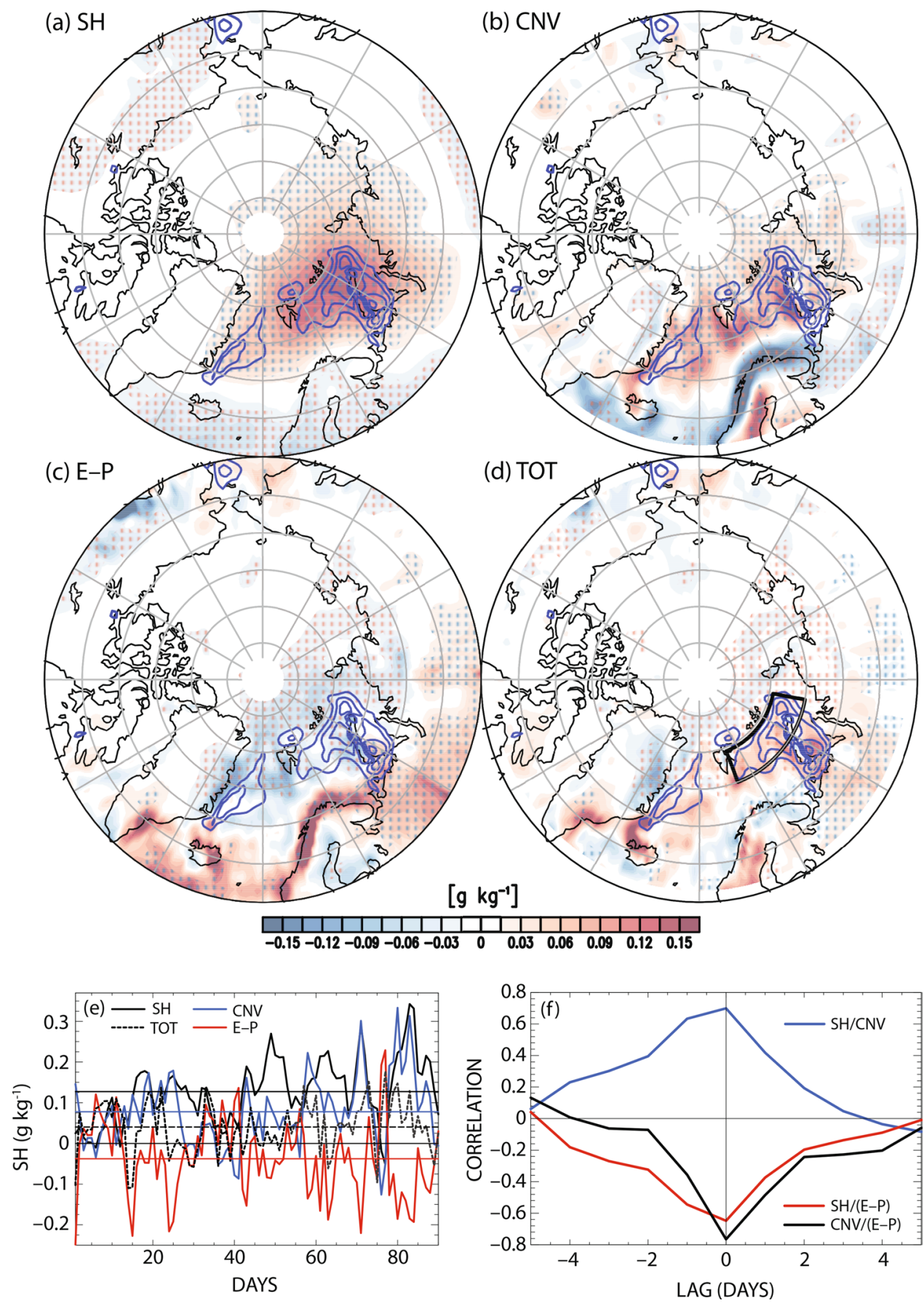

decreases specific humidity by $-0.037 \mathrm{~g} \mathrm{~kg}^{-1}$, contributing $-29.4 \%$ to SH. Thus, the net budget (TOT) explains only $+31.5 \%\left(+0.041 \mathrm{~g} \mathrm{~kg}^{-1}\right)$ of the mean anomalous moisture $\left(\mathrm{SH},+0.127 \mathrm{~g} \mathrm{~kg}^{-1}\right)$, significantly underestimating the specific humidity change during UB events. To assess the validity of budget calculation, moisture flux convergence is vertically integrated from 1000 to $1 \mathrm{hPa}$ and multiplied by the latent heat of vaporization $L_{\mathrm{v}}\left(2.26 \times 10^{6} \mathrm{~J} \mathrm{~kg}^{-1}\right)$. It turns out that the resulting pattern and magnitude (Fig. S3) are fairly similar to those in Gong and Luo (2017; Fig. 5a therein).
Figure 3 outlines the results of the thermal energy budget analysis associated with UB. Pattern of thermal advection (Fig. 3b) is analogous to that of moisture flux convergence (Fig. 2b), implying transports of warm and humid air over the BKS during UB events. A positive correlation $(+0.61)$ between air temperature and thermal advection (blue, Fig. 3f) hints that thermal advection significantly explains temperature variability during UB events. In contrast, turbulent and radiant flux together (Fig. 3c) exhibit negative anomalies where warm advection occurs. The opposite signs 
Fig. 3 Thermal energy budget in winter (DJF) in the lower troposphere (1000-850 hPa) associated with Ural blocking: a air temperature ( $\mathrm{T}), \mathbf{b}$ thermal advection (ADV), $\mathbf{c}$ turbulent (sensible + latent) plus radiant flux (SRC), $\mathbf{d}$ sum (TOT) of $\mathbf{b}$ and $\mathbf{c}$. Unit in $\mathbf{a}-\mathbf{d}$ is $\mathrm{K}$. $\mathbf{e}$ Daily variation of each variable with a straight line denoting its winter mean. f Lagged correlations between the variables in $\mathbf{e}$. Variables in $\mathbf{e}$ and $\mathbf{f}$ are area averages over $\left(21^{\circ}-79.5^{\circ}\right.$ E, $75^{\circ}-79.5^{\circ} \mathrm{N}$ ) (black box in Fig. 2d). Each variables' winter mean shown in $\mathbf{e}$ is the average of the 90 daily values in the time series. In $\mathbf{f}$, the first variable leads the second variable for a positive lag. Patterns over the dotted areas are significant at a $90 \%$ level
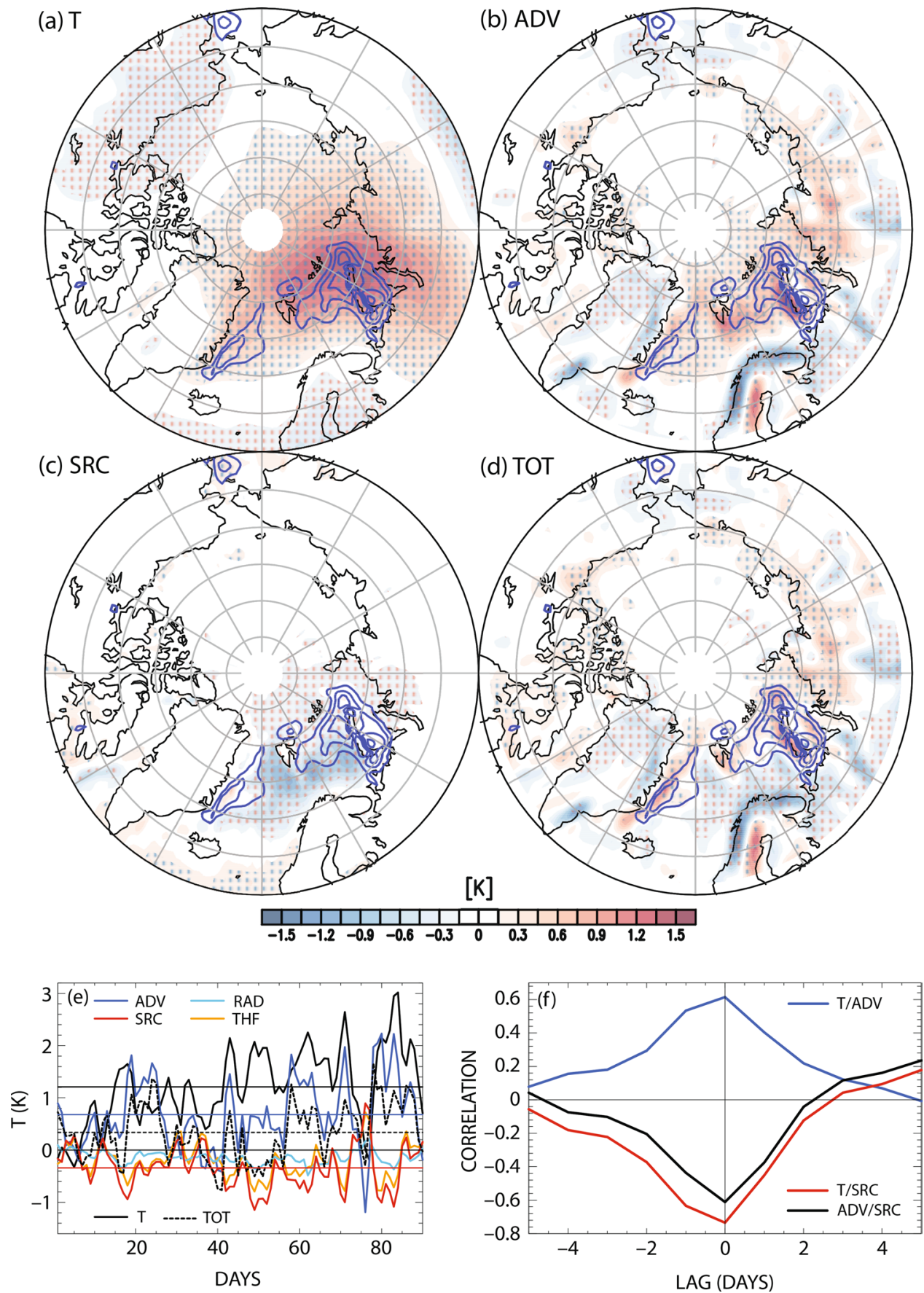

of the patterns in Fig. 3b, c can be interpreted in terms of the bulk aerodynamic formula (Friehe and Schmitt 1976). Specifically, since temperature and specific humidity differences between the surface and the atmosphere largely determines the magnitude of turbulent flux, warm and humid advection reduces the release of turbulent flux from the surface. Note that our interpretation of the weakened turbulent flux release is consistent with Lee et al. (2017) and Chen et al. (2018), where they interpreted the reduced sensible heat flux (SHF) release as a "downward" SHF originating from the atmosphere particularly over the Barents Sea. Like turbulent flux, anomalous longwave radiation (LW) also decreases thermal energy in the lower troposphere. The magnitude of downward LW at the surface exceeds upward LW so that the loss of thermal energy via LW in the air column is larger than the gain from the surface (see Fig. S4). This result is in line with the findings in Gong and Luo (2017) and Chen et al. (2018), who reported that a significant downward LW anomaly is observed during the lifecycle of UB. In addition, net LW at the top of the atmosphere is upward, decreasing 
thermal energy in the atmospheric column; consequently, a negative pattern is exhibited as in Fig. 3c. A negative correlation $(-0.61)$ between turbulent plus radiant flux (SRC) with the thermal advection (ADV) (black, Fig. 3f) also supports our interpretations. Additionally, a negative correlation $(-0.74)$ between the SRC and anomalous air temperature (red, Fig. 3f) indicates that anomalous warm temperature tends to increase downward longwave radiation at the surface and suppress the release of turbulent flux. Note that the effect of thermal advection which suppresses the turbulent heat flux by decreasing the vertical gradient of temperature at the surface outweighs the effect of increased downward longwave radiation which promotes the turbulent heat flux.

Figure $3 e$ shows the daily variation of each term of the thermal energy budget. Like moisture flux convergence, thermal advection (ADV), in the mean sense, increases temperature by $+0.679 \mathrm{~K}$, explaining $+56.1 \%$ of anomalous temperature (T). Meanwhile, turbulent and radiant flux together (SRC) tends to decrease temperature $(-0.342 \mathrm{~K})$, contributing $-28.2 \%$ to the anomalous temperature $(\mathrm{T})$. Net budget (TOT) explains $+27.9 \%(+0.337 \mathrm{~K})$ of the mean temperature anomaly $(\mathrm{T},+1.210 \mathrm{~K})$.

In summary, the budget analysis reveals that moisture and heat advection (CNV or ADV) by atmospheric circulation explains a considerable fraction of anomalous moisture and thermal energy in the lower troposphere during UB events. Indeed, moisture and heat transport from lower latitudes to the Arctic is a central mechanism of UB (Park et al. 2015; Woods and Caballero 2016; Pithan et al. 2018). In addition, surface sources of energy and moisture exhibit negative anomalies, particularly over the Barents Sea.

\subsection{Patterns of the sea ice loss mode associated with Arctic warming}

Figure 4 shows the winter average patterns of sea ice loss mode obtained via CSEOF analysis. Marked by its intensifying magnitude of amplitude time series (red, Fig. 9d), this mode will be called the "Arctic warming (AW) mode" in this study. Patterns of the AW mode exhibit both similarities and differences compared to those of UB. Anomalous air temperature and specific humidity are concentrated above the region of sea ice loss (Fig. 4a) as in the UB mode. These anomalies are particularly intense in the lower troposphere (Fig. 4c, d), elucidating a prominent feature of surface-based warmings in AW (Graversen et al., 2008; Serreze et al., 2009). However, the magnitudes of anomalous temperature, specific humidity, and meridional wind are larger than those associated with UB by twofold (see shading intervals in Figs. 1 and 4). Also, the core of anomalous temperature and specific humidity is shifted westward $\left(40^{\circ} \mathrm{E}\right)$ compared to the UB mode $\left(70^{\circ} \mathrm{E}\right)$ (Figs. 1c, 4c). Simultaneously, the center of geopotential height moved northeast $\left(75^{\circ} \mathrm{E}, 72.5^{\circ}\right.$ $\mathrm{N})$ compared to the UB mode $\left(60^{\circ} \mathrm{E}, 60^{\circ} \mathrm{N}\right)$ (Figs. 1b, 4b).

Figure 5 summarizes the moisture budget analysis associated with the AW mode. One of the most striking features in the AW mode is an intense moisture flux from the sea ice loss region. Excessive sea ice reduction exposes the open sea, releasing moisture via evaporation (red shading in Fig. 5c). In addition, precipitation is also increased in the vicinity of the sea ice retreat (blue shading in Fig. 5c). This result is in line with Bintanja and Selten (2014), who addressed the linkage between local evaporation and precipitation in the Arctic in association with sea ice retreat. The E-P pattern (Fig. 5c) shows an evident increase in moisture in the lower troposphere over the BKS. Furthermore, increased moisture flux convergence (Fig. 5b) is observed near the anomalous moisture (Fig. 5a). Note that the lagged correlation curves in Fig. $5 \mathrm{f}$ are analogous to those of the UB mode (Fig. 2f), implying that the daily variation (not the mean) in both the modes closely follow the bulk aerodynamic formula.

Figure $5 \mathrm{e}$ shows the daily variations of each term of the moisture budget associated with the AW mode. Moisture flux convergence $(\mathrm{CNV})$, in the mean sense, increases specific humidity by $+0.082 \mathrm{~g} \mathrm{~kg}^{-1}$, explaining $+40.7 \%$ of the anomalous moisture (SH). The source term, E-P, also raises specific humidity by $+0.115 \mathrm{~g} \mathrm{~kg}^{-1}$, contributing $+56.8 \%$ to the SH. The two terms (TOT) together explain $+97.5 \%\left(+0.197 \mathrm{~g} \mathrm{~kg}^{-1}\right)$ of the anomalous moisture $\left(\mathrm{SH},+0.202 \mathrm{~g} \mathrm{~kg}^{-1}\right)$ in the lower troposphere (1000-850 hPa). Accordingly, moisture budget analysis of the AW mode suggests that, on a sub-seasonal scale, the remote process $(\mathrm{CNV})$ contributes $+40.7 \%$ and the local process (E-P) $+56.8 \%$ to the anomalous moisture over the sea ice loss region in Fig. 5a. The positive contribution of the local process (source term) is the characteristic that strongly distinguishes the AW mode from the UB mode.

Figure 6 outlines the thermal energy budget analysis associated with the AW mode. Strong turbulent flux release is observed at the sea ice loss region (Fig. 6c). Recall that turbulent flux release plays a key role in the "insulation feedback" (Serreze et al. 2009; Deser et al. 2010; Screen et al. 2014; Kim et al. 2016, 2019); a strong contrast between AW and UB should be noted (see Figs. 3c and $6 \mathrm{c}$ ). Moreover, the longwave radiation (LW) patterns also exhibit differences compared to the UB case (see Fig. S4). Upward LW exceeds downward LW at the surface of the sea ice region so that the increased thermal energy warms the lower troposphere. Consequently, turbulent and radiant flux together (SRC, Fig. 6c) result in positive contribution in the mean sense over the sea ice loss region. Thermal advection (Fig. 6b) also shows anomalies of moderate amount compared to the turbulent plus radiant flux (SRC), contributing to the anomalous lower-tropospheric 
(a) AIRT \& SH $\left(0.03 \mathrm{~g} \mathrm{~kg}^{-1}\right)$

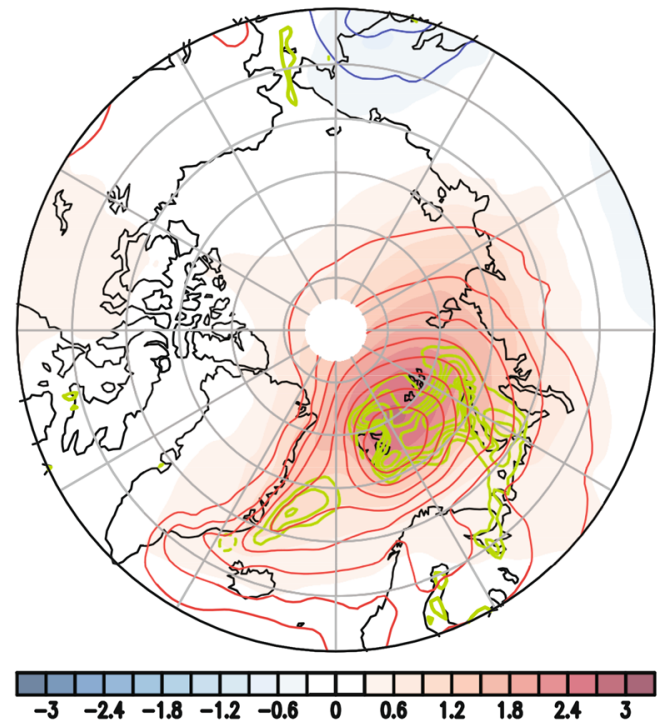

(b) GPH \& $(U, V)$

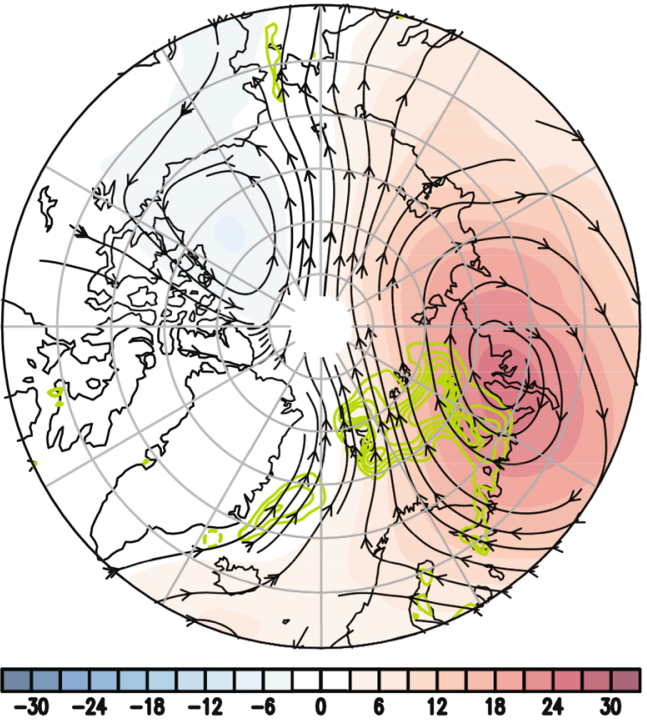

(d) $60^{\circ} \mathrm{E}$

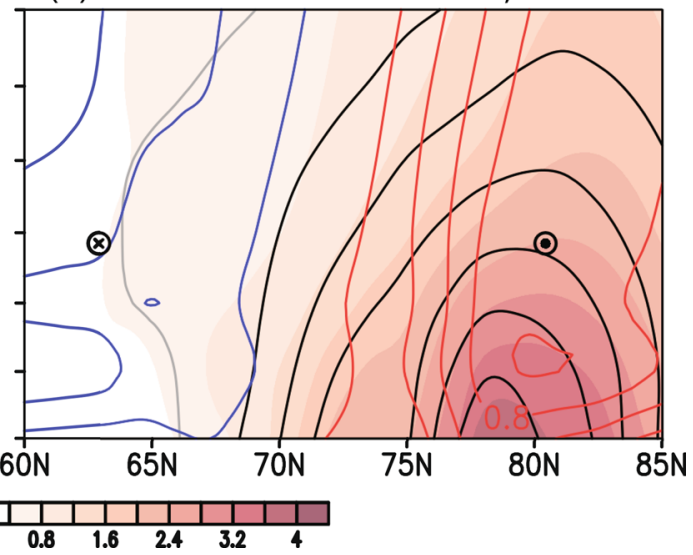

Fig. 4 Winter (DJF) average patterns in the lower troposphere (1000$850 \mathrm{hPa}$ ) associated with the AW (sea ice loss) mode: a air temperature (shading, $0.3 \mathrm{~K}$ interval), specific humidity (blue $<0<$ red contours at $0.03 \mathrm{~g} \mathrm{~kg}^{-1}$ interval), sea ice concentration loss (green contour, 5\%), b geopotential height (shading, $3 \mathrm{~m}$ ) and horizontal wind, c vertical cross-section of air temperature (shading, $0.4 \mathrm{~K}$ ), specific humidity (black contour, $0.04 \mathrm{~g} \mathrm{~kg}^{-1}$ ) and meridional wind (blue $<0<$ red contours, $\left.0.2 \mathrm{~m} \mathrm{~s}^{-1}\right)$ along $\left(0^{\circ}-120^{\circ} \mathrm{E}, 78^{\circ} \mathrm{N}\right)$, and $\mathbf{d}$ zonal wind (blue $<0<$ red contours, $\left.0.2 \mathrm{~m} \mathrm{~s}^{-1}\right)$ along $\left(60^{\circ} \mathrm{E}, 60^{\circ}-85^{\circ}\right.$ $\mathrm{N}$ ). The corresponding PC (amplitude) time series is normalized so that the patterns reflect the typical $(1 \sigma)$ magnitudes of the sea ice loss mode. Note the scales of shadings and contours are different from those of Fig. 1 temperature (Fig. 6a). Again, the lagged correlation curves (Fig. 6f) resemble those of UB (Fig. 3f), which indicates that daily variation (not the mean) closely follow the bulk aerodynamic formula.

Figure 6e shows the daily variation of each term in the thermal energy budget associated with the AW mode. Thermal advection (ADV) increases the lower-tropospheric temperature by $+0.603 \mathrm{~K}$ in the mean, explaining $+28.1 \%$ of anomalous temperature $(\mathrm{T})$. Turbulent and radiant flux together (SRC) raises air temperature by $+1.296 \mathrm{~K}$, explaining $+60.3 \%$ of the total anomaly (T). Net budget (TOT) explains $+88.3 \%(+1.899 \mathrm{~K})$ of the total temperature anomaly $(\mathrm{T},+2.149 \mathrm{~K})$. Accordingly, the budget analysis suggests that the local processes $(\mathrm{THF}+\mathrm{RAD}=\mathrm{SRC})$ account for the majority $(+60.3 \%)$ of the temperature anomalies and the remote process (ADV) to a lesser extent $(+28.1 \%)$.

By conducting the budget analysis, we deduced that (1) the winter-mean patterns of moisture and temperature anomalies are similar between the UB and the AW modes, (2) magnitudes of winter-mean moisture and temperature anomalies associated with the AW mode are stronger than those associated with UB, and (3) physical conditions leading to moisture and temperature anomalies are distinct. 
Fig. 5 Moisture budget analysis at winter (DJF) in the lower troposphere (1000-850 hPa) associated with the AW (sea ice loss) mode: a specific humidity (SH), b moisture flux convergence (CNV), $\mathbf{c}$ evaporation minus precipitation (E-P), $\mathbf{d}$ sum (TOT) of $\mathbf{b}$ and $\mathbf{c}$. Unit in a-d is $\mathrm{g} \mathrm{kg}^{-1}$. e Daily variation of each variable with a straight line denoting its winter mean. f Lagged correlations between the variables in e. Variables in $\mathbf{e}$ and $\mathbf{f}$ are area averages over $\left(21^{\circ}-79.5^{\circ}\right.$ E, $\left.75^{\circ}-79.5^{\circ} \mathrm{N}\right)$ (black box in Fig. 2d). Each variables' winter mean shown in e is the average of the 90 daily values in the time series. In $\mathbf{f}$, the first variable leads the second variable for a positive lag. Patterns over the dotted areas are significant at a $90 \%$ level
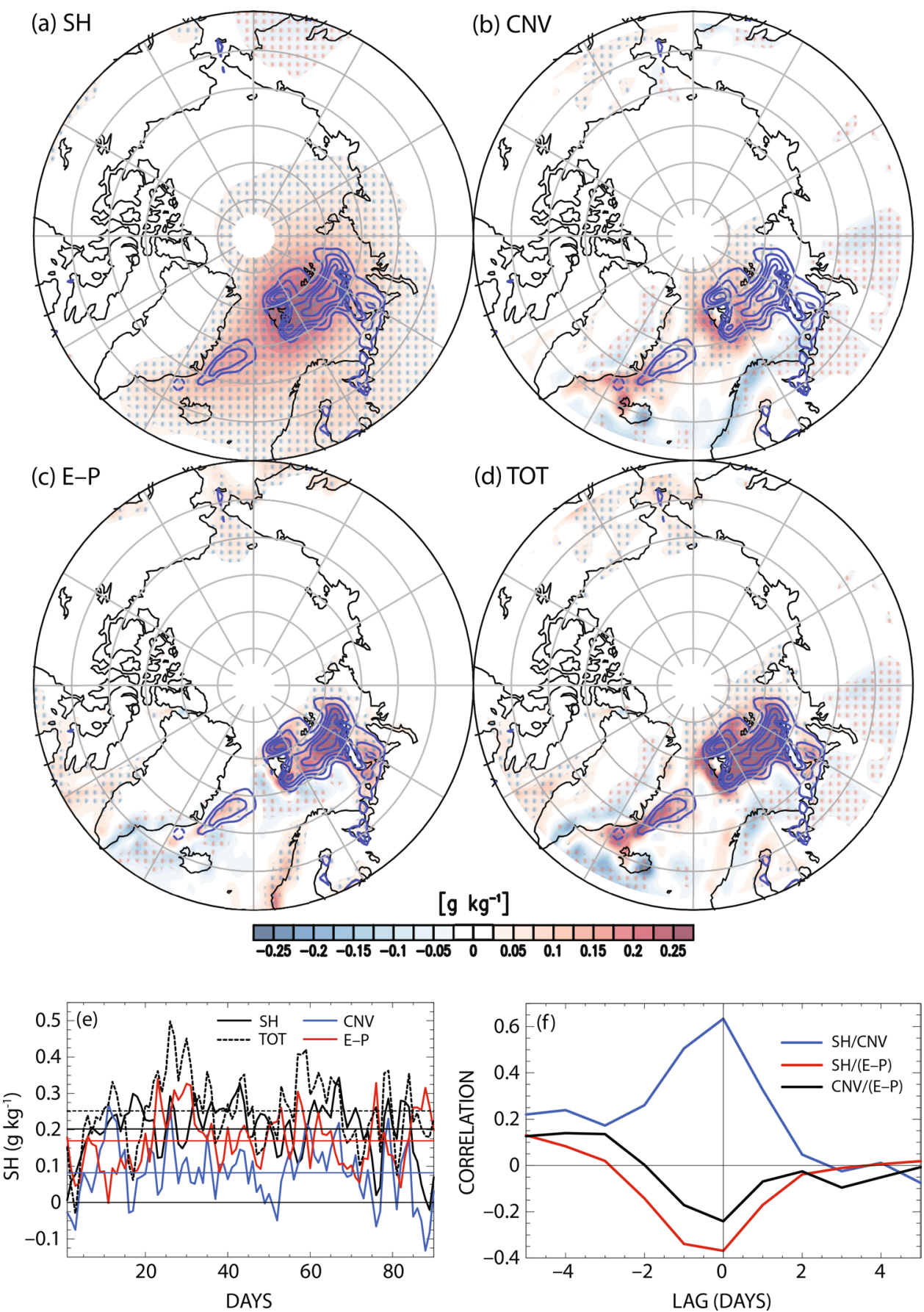

Specifically, the proportions of local and remote sources (moisture and heat) exhibit strong disparities between the two modes. The patterns of longwave radiation and turbulent flux are also in strong contrasts.

\subsection{Sub-seasonal link between Ural blocking and Arctic warming}

As an extension to Sects. 3.1 and 3.2, it is of interest to investigate how the UB and AW modes are linked on sub-seasonal scales. Gong and Luo (2017) mentioned that a two-way interaction may exist between UB and sea ice loss in the BKS (AW mode). To examine if this connection also holds in the present study, lower tropospheric physical conditions and circulation are presented in Fig. 7. An anticyclonic circulation pattern with negative vorticity is observed in the vicinity of anomalous high in both modes (Fig. 7a, b). Daily variations of air temperature and geopotential height averaged over the "centers" of action (boxed areas in Fig. 7a, b) are shown in Fig. 7c, d. A lead-lag correlation analysis 
Fig. 6 Thermal energy budget analysis at winter (DJF) in the lower troposphere (1000$850 \mathrm{hPa}$ ) associated with the AW (sea ice loss) mode: a air temperature (T), b thermal advection (ADV), $\mathbf{c}$ turbulent (sensible + latent $)$ plus radiant flux (SRC), $\mathbf{d}$ sum (TOT) of $\mathbf{b}$ and $\mathbf{c}$. Unit in $\mathbf{a}-\mathbf{d}$ is $\mathrm{K}$. e Daily variation of each variable with a straight line denoting its winter mean. f Lagged correlations between the variables in $\mathbf{e}$. Variables in $\mathbf{e}$ and $\mathbf{f}$ are area averages over $\left(21^{\circ}-79.5^{\circ}\right.$ $\mathrm{E}, 75^{\circ}-79.5^{\circ} \mathrm{N}$ ) (black box in Fig. 2d). Each variables' winter mean shown in $\mathbf{e}$ is the average of the 90 daily values in the time series. In $\mathbf{f}$, the first variable leads the second variable for a positive lag. Patterns over the dotted areas are significant at a $90 \%$ level
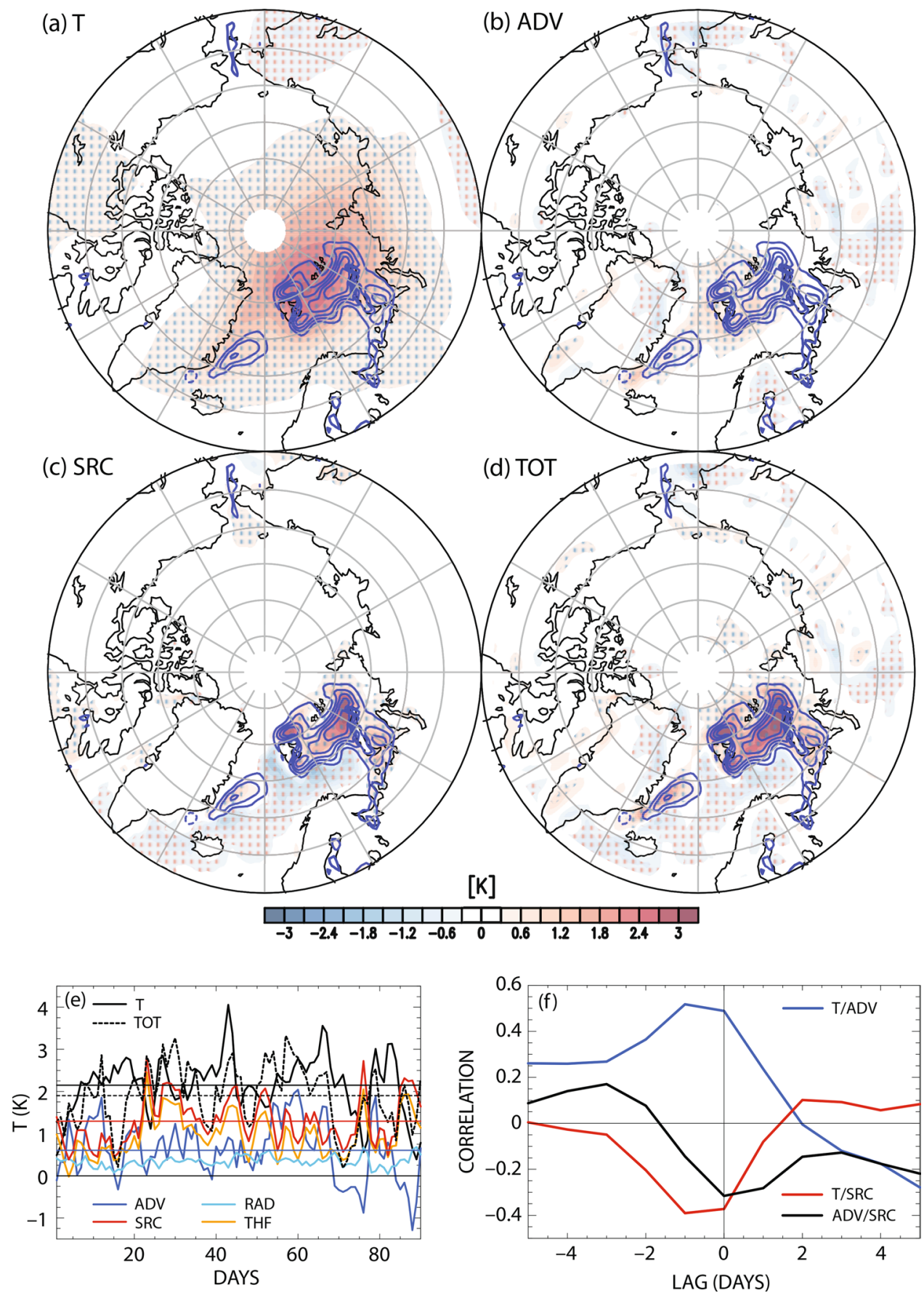

indicates that the air temperature is positively correlated with the geopotential height (UB: $+0.55, \mathrm{AW}:+0.60$ ) at zero lag. In addition, change in pressure layer thickness is calculated (Fig. 7e, f), which shows that the anomalies are nearly in hydrostatic balance in both modes. The winteraveraged atmospheric patterns hint that the two modes can influence each other, i.e., anomalous advection induced by UB affects AW and that produced by AW contributes to UB (see also Fig. S7).
Comparison of the winter average patterns cannot fully elucidate a possible link between the two modes. Thus, additional analysis is imperative comparing the two modes in terms of their sub-seasonal variability. To facilitate the comparison of the two modes, the following points should be noted: (1) winter-mean magnitude of each variable should be compared in order to assess its net effect; and (2) trend within the winter season is removed to focus only on short time-scale fluctuations. 
Fig. 7 Comparison of atmospheric circulation associated with the Ural blocking (UB) and the sea ice loss (AW) mode: winter-averaged pattern of temperature (shading, $0.15 \mathrm{~K}$ and $0.3 \mathrm{~K}$ intervals), and geopotential height (blue $<0<$ red contours at $3 \mathrm{~m}$ interval) in the lower troposphere (1000$850 \mathrm{hPa}$ ) associated with a the $\mathrm{UB}$ and $\mathbf{b}$ the AW modes. The green $\left(60^{\circ}-79.5^{\circ} \mathrm{E}, 73.5^{\circ}-79.5^{\circ}\right.$ $\mathrm{N}$ in a, $21^{\circ}-66^{\circ} \mathrm{E}, 78^{\circ}-84^{\circ} \mathrm{N}$ in b) and black $\left(51^{\circ}-72^{\circ} \mathrm{E}\right.$, $61.5^{\circ}-67.5^{\circ} \mathrm{N}$ in a, $63^{\circ}-84^{\circ} \mathrm{E}$, $69^{\circ}-75^{\circ} \mathrm{N}$ in b) boxes denote cores of anomalous air temperature and geopotential height, respectively. The light blue contours represent anomalous sea ice concentrations. $\mathbf{c}, \mathbf{d}$ Daily variation of the variables. In $\mathbf{c}$ and $\mathbf{d}$, air temperature (T) is averaged over the green box, and geopotential height $(\mathrm{GPH})$ is averaged over the black box. e, f Pressure layer thickness, $\Delta \mathrm{Z}=\mathrm{Z}\left(\mathrm{p}_{1}\right)-\mathrm{Z}\left(\mathrm{p}_{0}\right)$, calculated from the hydrostatic equation (contoured at $0.15 \mathrm{~m}$ and $0.3 \mathrm{~m}$ intervals) and that calculated from the geopotential height field (shading at $0.15 \mathrm{~m}$ and $0.3 \mathrm{~m}$ intervals) along $\left(60^{\circ}\right.$ E, $60^{\circ}-87^{\circ} \mathrm{N}$ ) (a) T (shade) \& Z (contour)
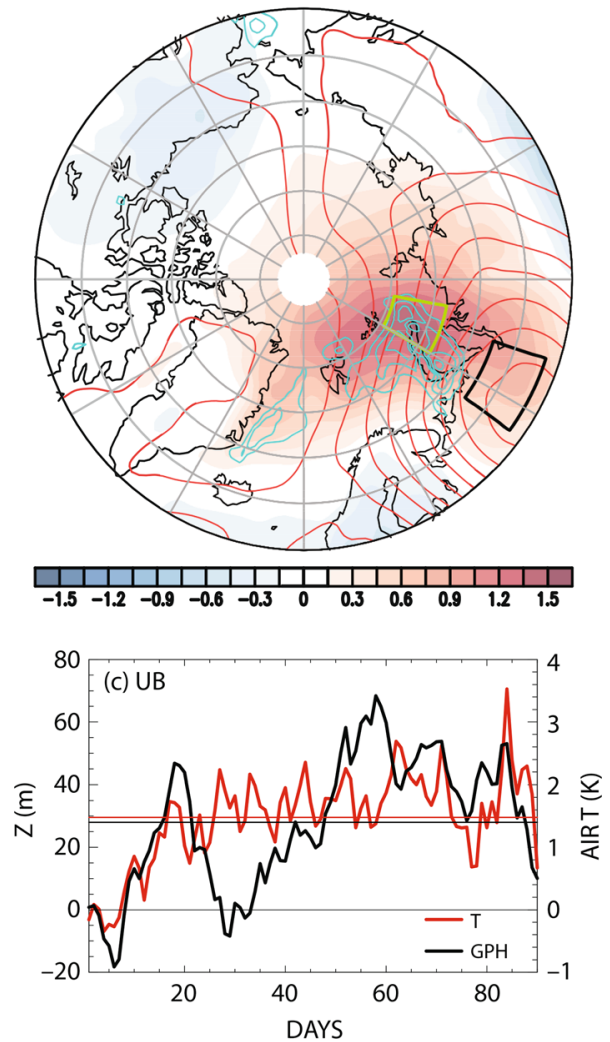

(e) UB: $60^{\circ} \mathrm{E}$

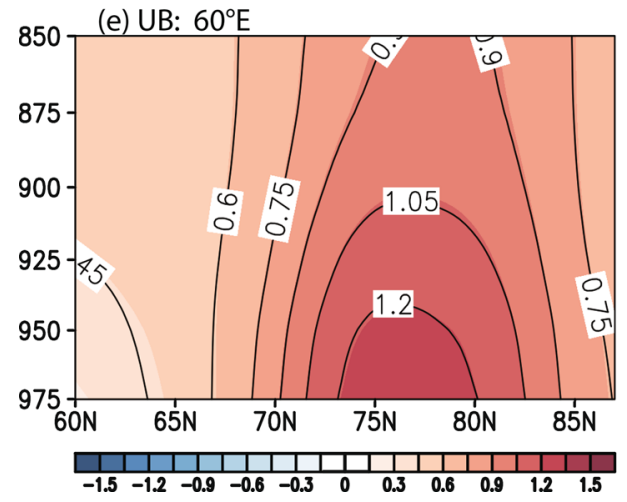

(b) $T$ (shade) \& Z (contour)
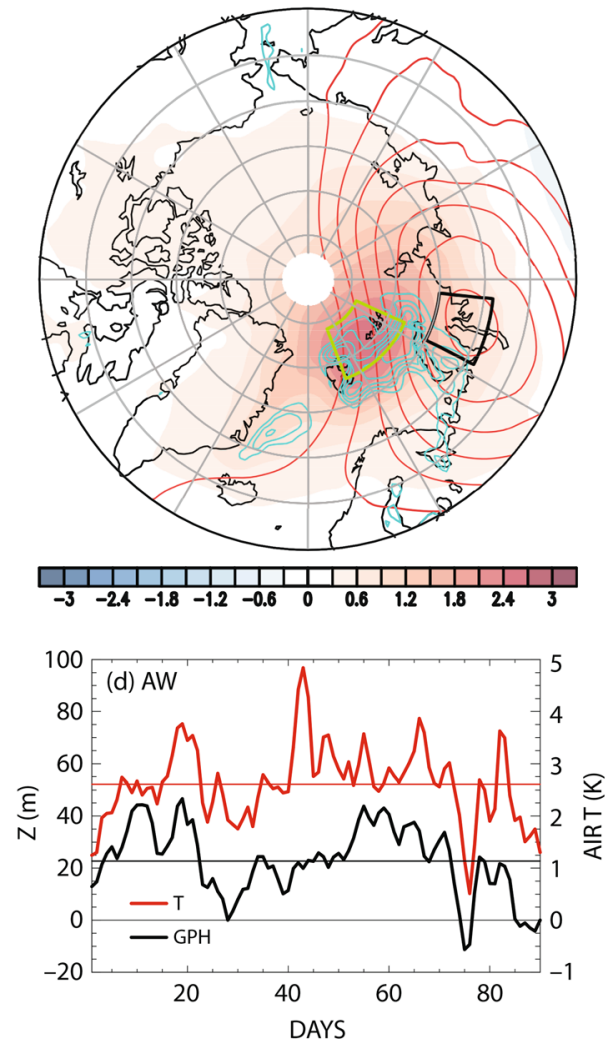

(f) $\mathrm{AW}: 60^{\circ} \mathrm{E}$

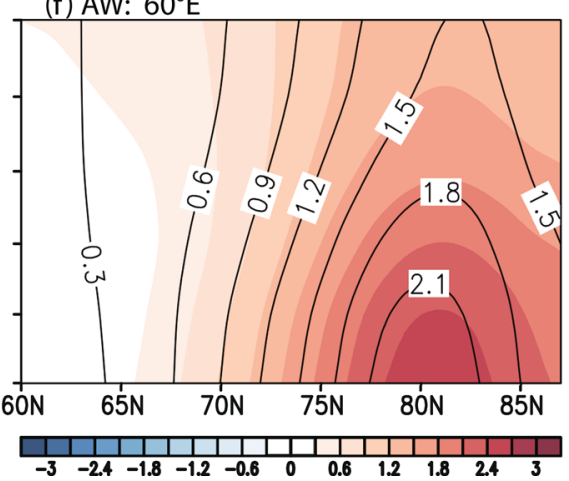

Over the region of sea ice reduction (Fig. 8a-f), convergence of moisture transport and horizontal heat advection show similar means (UB: $+0.078 \mathrm{~g} \mathrm{~kg}^{-1}, \mathrm{AW}:+0.082 \mathrm{~g} \mathrm{~kg}^{-1}$ for qCNV; UB: $+0.58 \mathrm{~K}$, AW: $+0.58 \mathrm{~K}$ for TADV) with correlations of +0.31 and +0.53 , respectively (Fig. $8 \mathrm{a}, \mathrm{b}$ ). This indicates that the transports of heat and moisture in the two modes have some similarity. On the other hand, a comparison of local source terms (E-P and THF) shows a striking difference. While weak positive correlations $(+0.26$ and +0.26$)$ are seen in Fig. 8 c, d, their mean magnitudes are of opposite signs (UB: $-0.04 \mathrm{~g} \mathrm{~kg}^{-1}$, AW: $+0.11 \mathrm{~g} \mathrm{~kg}^{-1}$ for E-P; UB: $-0.20 \mathrm{~K}, \mathrm{AW}:+1.03 \mathrm{~K}$ for THF). Note that thermal and moisture advection terms are negatively correlated with local source terms for both UB and AW (see negative correlations between ADV/SRC in Figs. 2f, 3f, 5f, 6f), which explains positive correlations in Fig. 8c, d despite the opposite signs of their means. As a result of opposite contributions of local sources, the mean magnitudes of anomalous temperature and specific humidity in the lower troposphere exhibit significant differences (Fig. 8e, f; UB: $+0.13 \mathrm{~g} \mathrm{~kg}^{-1}$, $\mathrm{AW}:+0.20 \mathrm{~g} \mathrm{~kg}^{-1}$ for q; $\mathrm{UB}:+1.21 \mathrm{~K}, \mathrm{AW}:+2.15 \mathrm{~K}$ for T), while their daily variations exhibit fair correlations $(+0.41$ and +0.56 ).

Figure $8 \mathrm{~g}$, h show the detrended time series of geopotential height and temperature in Fig. 7c, d (averaged over the centers of action). Geopotential height anomalies in both modes are comparable in the mean (UB: $+28 \mathrm{~m}, \mathrm{AW}:+23 \mathrm{~m}$ ) with a correlation value of +0.76 . 
Fig. 8 Detrended daily variations of variables in the UB and AW modes: a moisture flux convergence (qCNV), b horizontal thermal advection (TADV), c evaporation minus precipitation (E-P), $\mathbf{d}$ turbulent (sensible + latent) heat flux (THF), e lower-tropospheric specific humidity (q), f lowertropospheric temperature $(\mathrm{T}), \mathbf{g}$ geopotential height $(\mathrm{Z})$, and $\mathbf{h}$ lower-tropospheric temperature (T) at the centers of action. $\mathbf{g}$, $\mathbf{h}$ are detrended time series of Fig. $7 \mathrm{c}, \mathrm{d}$, and $\mathbf{a}-\mathbf{f}$ are detrended time series of Figs. 2e, 3e, 5e, and $6 \mathrm{e}$, respectively. A negative lag implies that AW leads UB
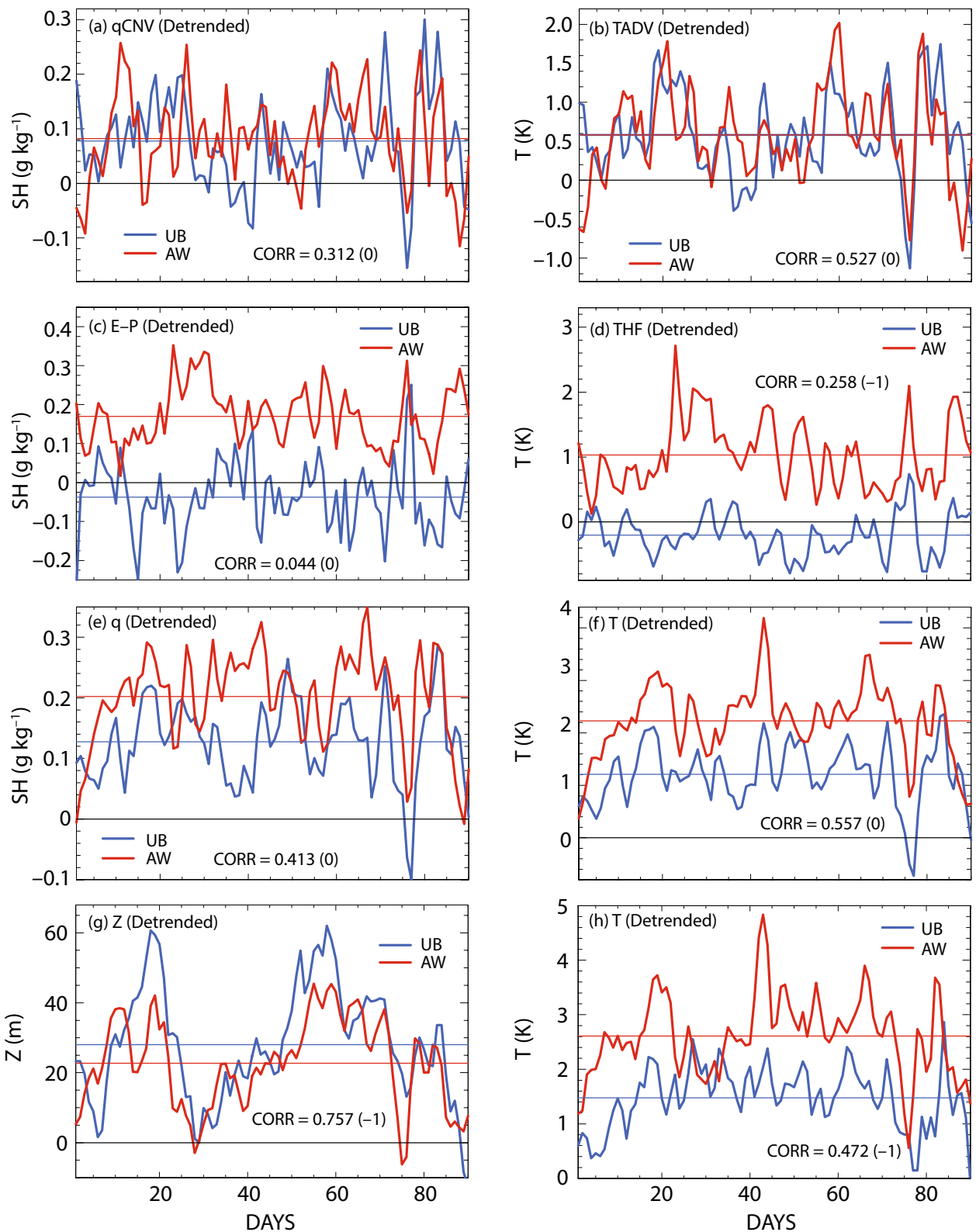

Temperature anomalies exhibit larger means in AW than in UB (UB: $+1.47 \mathrm{~K}, \mathrm{AW}:+2.61 \mathrm{~K}$ ) with a correlation value of +0.47 . Thus, anomalies associated with UB in the boxed areas in Fig. 7a and those associated AW in the boxed areas in Fig. 7b are reasonably correlated. The lag of maximum correlation indicates that AW leads UB slightly. It appears that the atmospheric circulation induced by AW exerts influence on UB (see also Figs. S5 and S7 and discussion therein). In turn, heat advection induced by UB seems to affect surface flux and tropospheric conditions (primarily temperature) associated with AW over the region of sea ice loss, as reflected in the non-negligible correlations in Fig. 8a-f (see also Fig. S6 and discussion therein). It appears that the two modes exert influences on one another at least to some extent. It should be pointed out that this link does not imply a cause-effect relationship between the two modes; detailed physical and dynamical picture of this interaction cannot be examined in the context of statistical analysis.

\subsection{Characteristics of sea ice loss associated with Ural blocking and Arctic warming}

To understand what leads to the substantial differences in the source terms (E-P and THF) between the two modes, sea ice variability is investigated due to its pivotal role in surface flux release. Figure 9 outlines the sea ice variability associated with each mode. The winter-averaged anomalous sea ice patterns in the UB (Fig. 9a) and the AW modes (Fig. 9b) 
Fig. 9 Comparison of sea ice variation in the UB and AW modes: winter-averaged pattern of sea ice concentration (SIC) change (shading) for a the UB and $\mathbf{b}$ the $\mathrm{AW}$ modes, $\mathbf{c}$ daily variation of SIC, $\mathbf{d}$ corresponding normalized amplitude time series with their trends (dashed lines), e actual change in sea ice concentration (black dotted), in comparison with the AW mode (black curve), the detrended AW mode (red curve), and the UB mode (blue curve). c-e represent area averages over $\left(21^{\circ}-79.5^{\circ} \mathrm{E}, 75^{\circ}-79.5^{\circ} \mathrm{N}\right)$ (black box in a). The curves in $\mathbf{e}$ are obtained by multiplying seasonal patterns in $\mathbf{c}$ with corresponding amplitude time series in $\mathbf{d}$ (a) UB SIC (1\%)
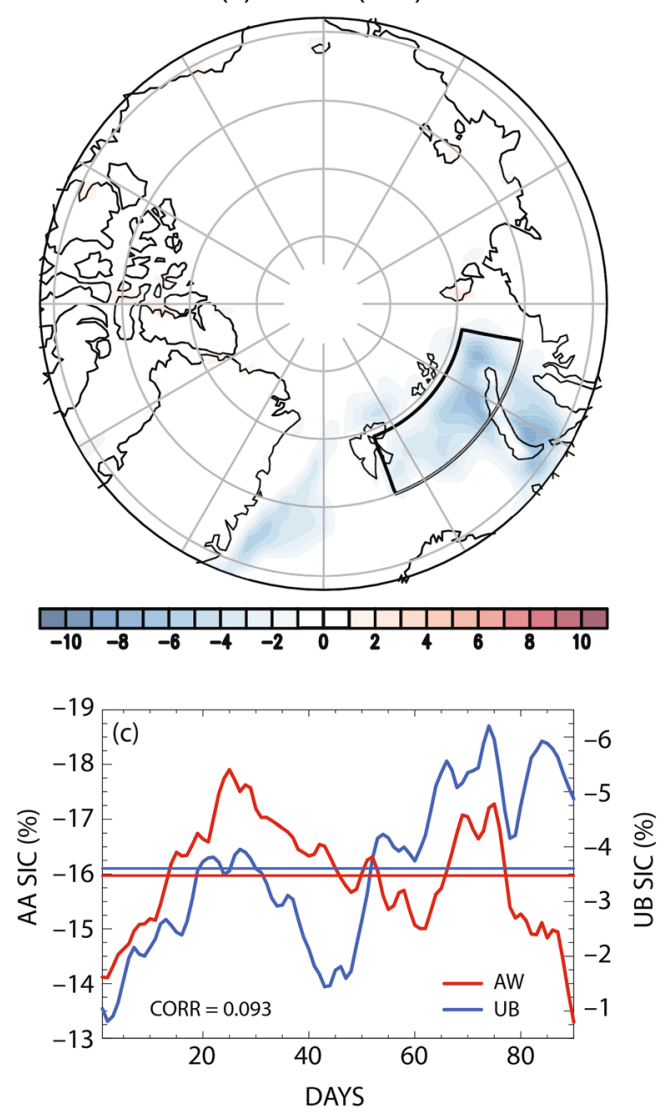

(b) AW SIC (3 \%)
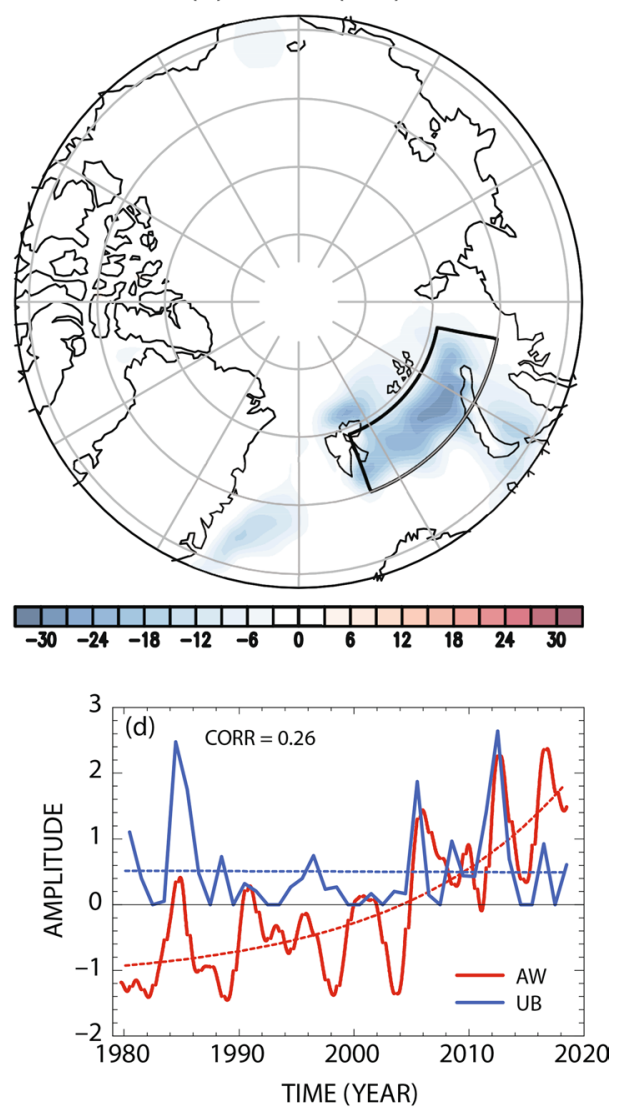

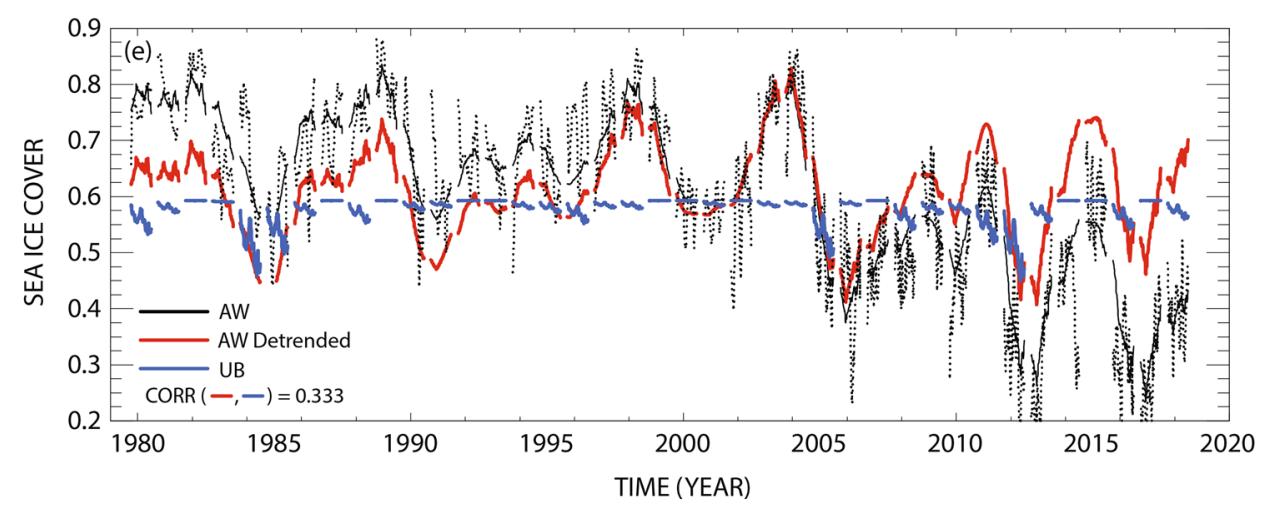

exhibit a locational resemblance. Although the daily SIC variations in Fig. 9c show little similarity, correlation value jumps to +0.38 when the trend within the winter season is removed (see Fig. S4). Thus, UB explains to some extent the sub-seasonal variation of sea ice loss in the BKS. Correlation of the amplitude time series in Fig. 9d also increases from +0.26 to +0.37 when the trend of the AW mode (red dotted curve) is removed (see Fig. S4).

While there is some resemblance between the two modes in terms of explaining sea ice variation on sub-seasonal and interannual scales (Fig. 9a-d), it is clear that UB cannot explain the long-term trend of the sea ice reduction in the BKS (black dotted curve, Fig. 9e). The amplitude time series of the AW mode increases exponentially at the rate of $~ 6.8 \%$ per year (red dashed curve in Fig. 9d; Kim et al. 2019), whereas no significant trend is observed in the amplitude time series of the UB mode (blue dotted curve, Fig. 9d). More importantly, UB explains only a small fraction of net sea ice loss in the BKS.

Figure 10 summarizes the evolution patterns of variables over the region of sea ice loss. Sporadic negative (downward) turbulent flux anomalies are observed in association with UB (Fig. 10a), whereas energetic upward turbulent flux is seen in the AW mode (Fig. 10e). The anomalous upward/downward longwave radiation and air temperature in the AW mode (Fig. 10f, g) are much 
Fig. 10 Longitude-time patterns associated with the Ural blocking (upper panels) and the sea ice loss (AW) mode (lower panels). a, e Turbulent (sensible + latent) heat flux, b, f upward longwave radiation at the surface (shading) and $2 \mathrm{~m}$ air temperature (contour), $\mathbf{c}, \mathbf{g}$ downward longwave radiation at the surface (shading) and $850 \mathrm{hPa}$ temperature (contour) $\mathbf{d}, \mathbf{h}$ sea ice concentration. All patterns are latitude-averaged over the region of sea ice reduction $\left(75^{\circ}-79.5^{\circ} \mathrm{N}\right)$. Days are counted from Dec. 1 (axes on the right side). Upward turbulent heat flux is defined as positive

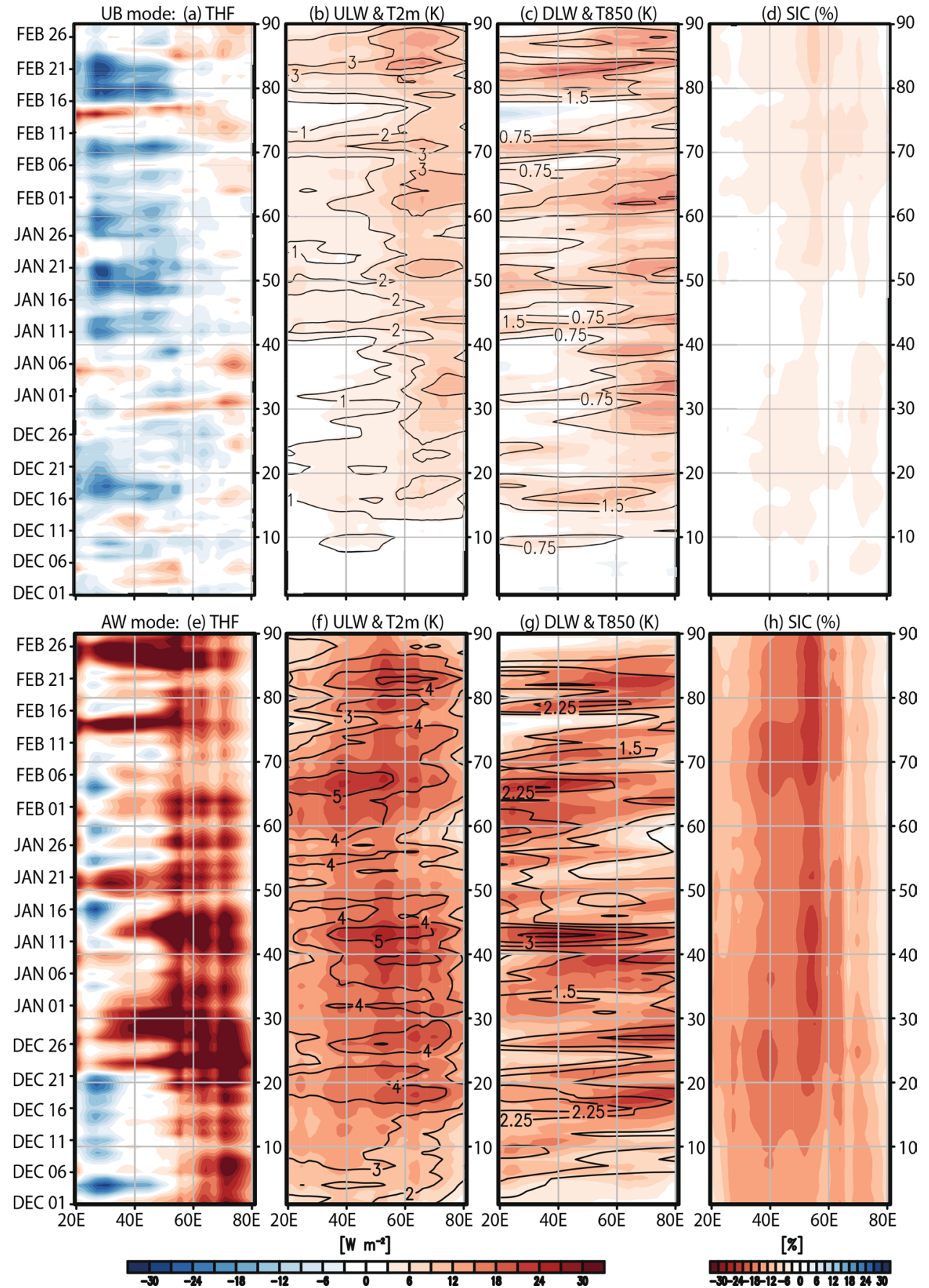

stronger than those of the UB mode (Fig. 10b, c), which is essentially due to the vertical feedback mechanism as a result of strong turbulent heat flux in the AW mode (Kim and Kim 2019; Kim et al. 2019). On the other hand, heat advection is the "primary" mechanism during UB events, leading to relatively small increase in temperature and longwave radiation. The UB mode lacks the vertical feedback mechanism due to the negative turbulent heat flux anomalies induced by the warm and moist advection. The presence/absence of the vertical feedback process explains the disparity in the mean magnitudes of the anomalous SIC (AW: $-15.9 \%$, UB: $-3.6 \%$ ) in the two modes. Earlier studies report that the magnitude of sea ice loss during the lifecycle of UB is less than $-10 \%$ (Gong and Luo 2017; Chen et al. 2018; Peings 2019), which is generally in line with our findings.

In summary, sub-seasonal variation of SIC in the BKS is partly linked with UB. On the other hand, AW essentially sets the mean of SIC change and partly shares subseasonal variability with UB. In fact, the characteristics 
of sea ice loss associated with the UB and the AW modes can be understood within the framework of "forced climate change" and "natural variability". Although separating forced climate change and natural variability associated with Arctic sea ice change is a challenging task (Cohen et al. 2014), it is suggested that UB represents natural variability whereas AW depicts primarily forced climate variability judging by the long-term trends in the amplitude time series (blue and red dashed curves in Fig. 9d) and the associated changes in SIC (Fig. 9e). The significant trend associated with AW is essentially due to the vertical feedback at the interface of the atmosphere and the ocean (Kim and Kim 2019). It should be pointed out that heat transport by the warm Norwegian current may be a likely mechanism for keeping the sea surface from freezing due to the net loss of energy over the open sea surface (Årthun et al. 2012; Onarheim et al. 2015; Schlichtholz 2011; Smedsrud et al. 2013).

\section{Concluding remarks}

The purpose of this research is to delineate the role of Ural blocking (UB) on sea ice concentration in the Barents-Kara Seas (BKS) and to investigate any connections with Arctic warming (AW) in winter (DJF). To elucidate the
Fig. 11 Schematic diagram of the moisture $(\mathrm{SH})$ and thermal energy ( $\mathrm{T}$ ) budget analysis associated with the Ural blocking (UB) and sea ice loss (AW) modes

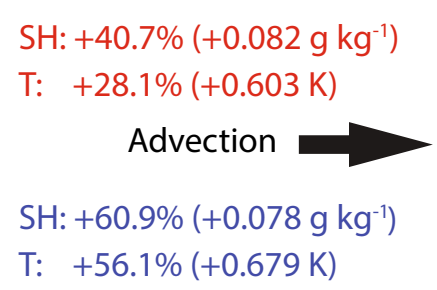

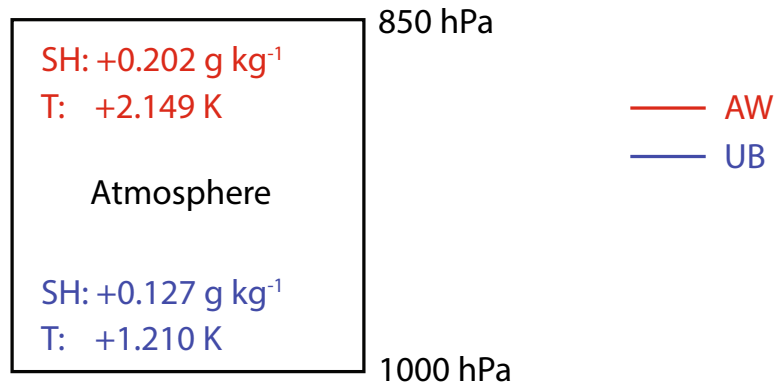

$1000 \mathrm{hPa}$

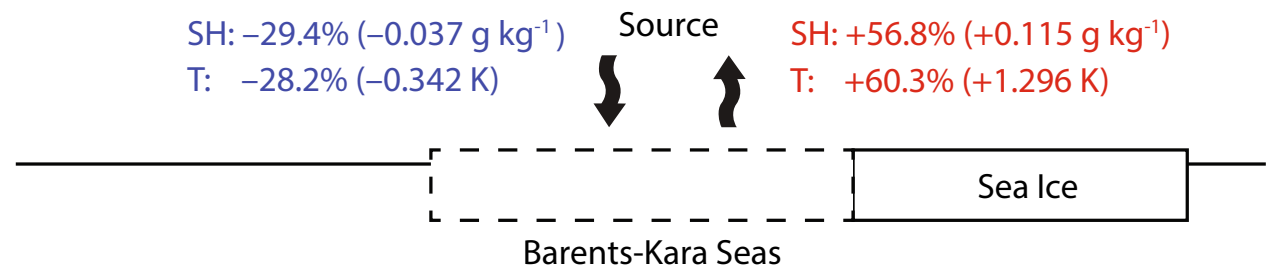

Table 1 Summary of moisture and thermal energy budget analysis associated with the Ural blocking (UB) and CSEOF Arctic warming (AW) modes

\begin{tabular}{|c|c|c|c|c|}
\hline \multirow{2}{*}{$\begin{array}{l}\text { Winter }(\mathrm{DJF}) \\
1979-2018 \\
\text { Lower troposphere } \\
(1000-850 \mathrm{hPa})\end{array}$} & \multicolumn{2}{|l|}{ Moisture budget } & \multicolumn{2}{|c|}{ Thermal energy budget } \\
\hline & $\begin{array}{l}\text { Remote process } \\
\text { (moist flux convergence) }\end{array}$ & $\begin{array}{l}\text { Local process } \\
\text { (evaporation - precipitation) }\end{array}$ & $\begin{array}{l}\text { Remote process } \\
\text { (thermal advection) }\end{array}$ & $\begin{array}{l}\text { Local process } \\
\text { (sensible/latent } \\
\text { heat + radiation) }\end{array}$ \\
\hline Ural blocking & $\begin{array}{l}+\mathbf{6 0 . 9} \% \\
\left(+0.078 \mathrm{~g} \mathrm{~kg}^{-1}\right) \\
\sigma=0.0862 \mathrm{~g} \mathrm{~kg}^{-1} \\
\text { Sum of remote and local } \mathrm{p} \\
\left(+0.041 \mathrm{~g} \mathrm{~kg}^{-1} /+0.127 \mathrm{~g}\right.\end{array}$ & $\begin{array}{l}-\mathbf{2 9 . 4} \% \\
\left(-0.037 \mathrm{~g} \mathrm{~kg}^{-1}\right) \\
\sigma=0.0945 \mathrm{~g} \mathrm{~kg}^{-1} \\
31.5 \%\end{array}$ & $\begin{array}{l}+\mathbf{5 6 . 1} \% \\
(+0.679 \mathrm{~K}) \\
\sigma=0.6798 \mathrm{~K} \\
\text { Sum of remote and } 1 \\
(+0.337 \mathrm{~K} /+1.210\end{array}$ & $\begin{array}{l}-\mathbf{2 8 . 2} \% \\
(-0.342 \mathrm{~K}) \\
\sigma=0.4109 \mathrm{~K} \\
\text { cesses: }+27.9 \%\end{array}$ \\
\hline $\begin{array}{l}\text { CSEOF } \\
\text { AW mode }\end{array}$ & $\begin{array}{l}+\mathbf{4 0 . 7} \% \\
\left(+0.082 \mathrm{~g} \mathrm{~kg}^{-1}\right) \\
\sigma=0.0825 \mathrm{~g} \mathrm{~kg}^{-1}\end{array}$ & $\begin{array}{l}+\mathbf{5 6 . 8} \% \\
\left(+0.115 \mathrm{~g} \mathrm{~kg}^{-1}\right) \\
\sigma=0.1256 \mathrm{~g} \mathrm{~kg}^{-1}\end{array}$ & $\begin{array}{l}+28.1 \% \\
(+0.603 \mathrm{~K}) \\
\sigma=0.6978 \mathrm{~K}\end{array}$ & $\begin{array}{l}+60.3 \% \\
(+1.296 \mathrm{~K}) \\
\sigma=0.5601 \mathrm{~K}\end{array}$ \\
\hline & \multicolumn{2}{|c|}{$\begin{array}{l}\text { Sum of remote and local processes: }+97.5 \% \\
\left(+0.197 \mathrm{~g} \mathrm{~kg}^{-1} /+0.202 \mathrm{~g} \mathrm{~kg}^{-1}\right)\end{array}$} & \multicolumn{2}{|c|}{$\begin{array}{l}\text { Sum of remote and local processes: }+88.4 \% \\
(+1.899 \mathrm{~K} /+2.149 \mathrm{~K})\end{array}$} \\
\hline
\end{tabular}

The percentage in bold represents the fraction of the total mean explained by each process, which is enclosed in parentheses. The symbol $\sigma$ denotes one standard deviation level of fluctuation in the daily time series of each process averaged over the region $\left(21^{\circ}-79.5^{\circ} \mathrm{E}, 75^{\circ}-79.5^{\circ} \mathrm{N}\right)$ 
characteristics of UB and its connection with sea ice retreat in the BKS, variables are projected onto the UB index to obtain the patterns during UB events. As a counterpart to the UB mode, CSEOF analysis is conducted to obtain the sea ice loss mode, together with the physically consistent patterns of other variables. This so-called Arctic warming (AW) mode with an amplifying PC (amplitude) time series is compared with the UB mode. This approach enables us to address the relative impacts of UB and AW on sea ice cover in the BKS and a possible physical link between them.

Based on the moisture and thermal energy budget analysis, it is suggested that the impact of UB on sea ice in the BKS is mainly through the large-scale atmospheric circulation (remote process) while that of AW is driven by the atmosphere-ocean surface interaction (local process); the budget analysis is summarized as a schematic diagram in Fig. 11 and Table 1. Analysis shows that the local process explains more than the remote process of the anomalous moisture (local: $+56.8 \%$, remote: $+40.7 \%$ ) and thermal energy (local: $+60.3 \%$, remote: $+28.1 \%$ ) in the AW mode. Meanwhile, the remote process becomes more dominant than the local process in explaining the change in moisture (remote: $+60.9 \%$, local: $-29.4 \%$ ) and thermal energy (remote: $+56.1 \%$, local: $-28.2 \%$ ) in the UB mode. Also, the patterns of anomalous turbulent heat flux and anomalous moisture flux (E-P) are of opposite signs. While the UB index explains temperature and moisture advection over the region of sea ice reduction to some degree, it cannot account for the local vertical feedback process reasonably as reflected in the negative contributions of the local processes. Considering the signs of mean surface flux (Fig. 11), processes occurring at the ocean-atmosphere interface are substantially different between the two modes.

On the other hand, the UB and the AW modes show similar atmospheric circulation patterns. The winter average patterns show that the anomalous air temperature and geopotential height are in hydrostatic balance. These circulation patterns may affect each other, implying a twoway interaction between UB and AW over the BKS as mentioned by Gong and Luo (2017). The sub-seasonal variation in the budget equations shows that the terms associated with the remote processes are similar in magnitude between the two modes, and have relatively high correlations compared to those of the local processes. Thus, the UB and the AW modes exhibit analogous large-scale atmospheric circulation patterns but distinctive atmosphere-ocean surface interactions.

UB explains a moderate fraction of sub-seasonal SIC variability, but cannot explain the long-term trend and the mean magnitude of sea ice loss in the BKS. The gap between the UB and the AW modes can be explained in terms of the "insulation feedback" (Serreze et al. 2009;
Deser et al. 2010; Screen et al. 2014; Kim et al. 2016, 2019). In the AW mode, release of turbulent and moisture flux at the open sea surface warms the lower troposphere and increases downward longwave radiation in the mean sense. Increased downward longwave radiation intensifies sea ice retreat, broadening open sea surface, and triggering an increase in turbulent flux, which essentially constitutes the vertical feedback mechanism (Kim et al. 2019). In the UB mode, on the other hand, sea ice loss in the BKS largely relies on the transport of warm and humid air from mid-latitudes (Park et al. 2015; Woods and Caballero 2016; Pithan et al. 2018), which reduces turbulent heat flux. Consequently, the insulation feedback process cannot be established.

Acknowledgements This study was supported by the National Research Foundation of Korea Grant (NRF-2020R1A2B5B01002600).

Open Access This article is licensed under a Creative Commons Attribution 4.0 International License, which permits use, sharing, adaptation, distribution and reproduction in any medium or format, as long as you give appropriate credit to the original author(s) and the source, provide a link to the Creative Commons licence, and indicate if changes were made. The images or other third party material in this article are included in the article's Creative Commons licence, unless indicated otherwise in a credit line to the material. If material is not included in the article's Creative Commons licence and your intended use is not permitted by statutory regulation or exceeds the permitted use, you will need to obtain permission directly from the copyright holder. To view a copy of this licence, visit http://creativecommons.org/licenses/by/4.0/.

\section{References}

Årthun M, Eldevik T, Smedsrud LH, Skagseth $\emptyset$, Ingvaldsen RB (2012) Quantifying the influence of Atlantic heat on Barents Sea ice variability and retreat. J Clim 25:4736-4743

Barnes EA (2013) Revisiting the evidence linking Arctic amplification to extreme weather in midlatitudes. Geophys Res Lett 40:47284733. https://doi.org/10.1002/grl.50880

Bintanja R, Selten F (2014) Future increases in Arctic precipitation linked to local evaporation and sea-ice retreat. Nature 509:479482. https://doi.org/10.1038/nature13259

Blackport R, Screen JA (2020) Insignificant effect of Arctic amplification on the amplitude of midlatitude atmospheric waves. Sci Adv 6:8. https://doi.org/10.1126/sciadv.aay2880

Chen X, Luo D, Feldstein SB, Lee S (2018) Impact of winter Ural blocking on Arctic sea ice: short-time variability. J Clim 31:22672282. https://doi.org/10.1175/jcli-d-17-0194.1

Cheung HHN, Zhou W (2015) Implications of Ural blocking for east Asian winter climate in CMIP5 GCMs part I: biases in the historical scenario. J Clim 28:2203-2216. https://doi.org/10.1175/ jcli-d-14-00308.1

Cohen J, Screen JA, Furtado JC et al (2014) Recent Arctic amplification and extreme mid-latitude weather. Nat Geosci 7:627-637. https://doi.org/10.1038/ngeo2234

Cohen J, Zhang X, Francis J et al (2020) Divergent consensuses on Arctic amplification influence on midlatitude severe winter weather. Nat Clim Change 10:20-29. https://doi.org/10.1038/ s41558-019-0662-y 
Comiso JC (2012) Large decadal decline of the Arctic multiyear ice cover. J Clim 25:1176-1193. https://doi.org/10.1175/jclid-11-00113.1

Dai A, Song M (2020) Little influence of Arctic amplification on mid-latitude climate. Nat Clim Change 10:231-237. https://doi. org/10.1038/s41558-020-0694-3

Dee DP, Uppala SM, Simmonds AJ et al (2011) The ERA-interim reanalysis: configuration and performance of the data assimilation system. Q J R Meteorol Soc 137:553-597

Deser C, Tomas R, Alexander M, Lawrence D (2010) The seasonal atmospheric response to projected Arctic sea ice loss in the late twenty-first century. J Clim 23:333-351. https://doi. org/10.1175/2009jcli3053.1

Francis JA, Hunter E (2006) New insight into the disappearing Arctic sea ice. Eos Trans Am Geophys Union 87:509-511. https://doi. org/10.1029/2006eo460001

Francis JA, Vavrus SJ (2012) Evidence linking Arctic amplification to extreme weather in mid-latitudes. Geophys Res Lett 39:L06801. https://doi.org/10.1029/2012gl051000

Friehe CA, Schmitt KF (1976) Parameterization of air-sea interface fluxes of sensible heat and moisture by the bulk aerodynamic formulas. J Phys Oceanogr 6:801-809. https://doi.org/10.1175/15200485(1976)006\%3c0801:poasif\%3e2.0.co;2

Gong T, Luo D (2017) Ural blocking as an amplifier of the Arctic sea ice decline in winter. J Clim 30:2639-2654. https://doi. org/10.1175/jcli-d-16-0548.1

Graversen R, Mauritsen T, Tjernström M et al (2008) Vertical structure of recent Arctic warming. Nature 451:53-56. https://doi. org/10.1038/nature06502

Kim JY, Kim KY (2019) Relative role of horizontal and vertical processes in the physical mechanism of wintertime Arctic amplification. Clim Dyn 52:6097-6107. https://doi.org/10.1007/s0038 2-018-4499-2

Kim KY, North GR, Huang J (1996) EOFs of one-dimensional cyclostationary time series: computations, examples, and stochastic modeling. J Atmos Sci 53:1007-1017. https://doi. org/10.1175/1520-0469(1996)053\%3c1007:eoodct\%3e2.0.co;2

Kim KY, North GR (1997) EOFs of harmonizable cyclostationary processes. J Atmos Sci 54:2416-2427. https://doi.org/10.1175/15200469(1997)054\%3c2416:eohcp\%3e2.0.co;2

Kim KY, Hamlington BD, Na H (2015) Theoretical foundation of cyclostationary EOF analysis for geophysical and climatic variables: concepts and examples. Earth Sci Rev 150:201-218. https ://doi.org/10.1016/j.earscirev.2015.06.003

Kim KY, Hamlington BD, Na H, Kim J (2016) Mechanism of seasonal Arctic sea ice evolution and Arctic amplification. Cryosphere 10:2191-2202. https://doi.org/10.5194/tc-10-2191-2016

Kim KY, Kim JY, Kim J, Yeo S, Na H, Hamlington BD, Leben RR (2019) Vertical feedback mechanism of winter Arctic amplification and sea ice loss. Sci Rep 9:1184. https://doi.org/10.1038/ s41598-018-38109-x

Kug JS, Jeong JH, Jang YS et al (2015) Two distinct influences of Arctic warming on cold winters over North America and East Asia. Nat Geosci 8:759-762. https://doi.org/10.1038/ngeo2517

Lee S, Gong T, Feldstein SB et al (2017) Revisiting the cause of the 1989-2009 Arctic surface warming using the surface energy budget: downward infrared radiation dominates the surface fluxes. Geophys Res Lett 44:10654-10661. https://doi.org/10.1002/2017g 1075375

Mori M, Watanabe M, Shiogama H et al (2014) Robust Arctic sea-ice influence on the frequent Eurasian cold winters in past decades. Nat Geosci 7:869-873. https://doi.org/10.1038/ngeo2277

Onarheim IH, Eldevik T, Årthun M, Ingvaldsen RB, Smedsrud LH (2015) Skillful prediction of Barents Sea ice cover. Geophys Res Lett 42:5364-5371
Overland JE, Wood KR, Wang M (2011) Warm Arctic_cold continents: climate impacts of the newly open Arctic sea. Polar Res 30:15787. https://doi.org/10.3402/polar.v30i0.15787

Park HS, Lee S, Son SW et al (2015) The impact of poleward moisture and sensible heat flux on Arctic winter sea ice variability. J Clim 28:5030-5040. https://doi.org/10.1175/jcli-d-15-0074.1

Peings Y (2019) Ural blocking as a driver of early-winter stratospheric warmings. Geophys Res Lett 46:5460-5468. https://doi. org/10.1029/2019g1082097

Petoukhov V, Semenov VA (2010) A link between reduced BarentsKara sea ice and cold winter extremes over northern continents. J Geophys Res 115:D21111. https://doi.org/10.1029/2009jd013568

Pithan F, Mauritsen T (2014) Arctic amplification dominated by temperature feedbacks in contemporary climate models. Nat Geosci 7:181-184. https://doi.org/10.1038/ngeo2071

Pithan F, Svensson G, Caballero R et al (2018) Role of air-mass transformations in exchange between the Arctic and mid-latitudes. Nat Geosci 11:805-812. https://doi.org/10.1038/s41561-018-0234-1

Schlichtholz P (2011) Influence of oceanic heat variability on sea ice anomalies in the Nordic Seas. Geophys Res Lett 38:L05705. https ://doi.org/10.1029/2010GL045894

Screen JA, Simmonds I (2010) The central role of diminishing sea ice in recent Arctic temperature amplification. Nature 464:13341337. https://doi.org/10.1038/nature09051

Screen JA, Deser C, Simmonds I (2012) Local and remote controls on observed Arctic warming. Geophys Res Lett 39:L10709. https:// doi.org/10.1029/2012g1051598

Screen JA, Deser C, Simmonds I et al (2014) Atmospheric impacts of Arctic sea-ice loss, 1979-2009: separating forced change from atmospheric internal variability. Clim Dyn 43:333-344. https:// doi.org/10.1007/s00382-013-1830-9

Screen JA (2017) Simulated atmospheric response to regional and panArctic sea ice loss. J Clim 30:3945-3962. https://doi.org/10.1175/ jcli-d-16-0197.1

Serreze MC, Barrett AP, Stroeve JC et al (2009) The emergence of surface-based Arctic amplification. Cryosphere 3:11-19. https:// doi.org/10.5194/tc-3-11-2009

Singarayer JS, Valdes PJ, Bamber JL (2005) The atmospheric impact of uncertainties in recent Arctic sea ice reconstructions. J Clim 18:3996-4012. https://doi.org/10.1175/jcli3490.1

Smedsrud LH et al (2013) The role of the Barents Sea in the Arctic climate system. Rev Geophys 15:415-449

Stroeve JC, Serreze MC, Holland MM et al (2011) The Arctic's rapidly shrinking sea ice cover: a research synthesis. Clim Change 110:1005-1027. https://doi.org/10.1007/s10584-011-0101-1

Tibaldi S, Molteni F (1990) On the operational predictability of blocking. Tellus A 42:343-365. https://doi. org/10.1034/j.1600-0870.1990.t01-2-00003.x

Tyrlis E, Manzini E, Bader J et al (2019) Ural blocking driving extreme Arctic sea ice loss, cold Eurasia, and stratospheric vortex weakening in autumn and early winter 2016-2017. J Geophys Res Atmos 124:11313-11329. https://doi.org/10.1029/2019jd031085

Woods C, Caballero R (2016) The role of moist intrusions in winter Arctic warming and sea ice decline. J Clim 29:4473-4485. https ://doi.org/10.1175/jcli-d-15-0773.1

Woollings T, Barriopedro D, Methven J et al (2018) Blocking and its response to climate change. Curr Clim Change Rep 4:287-300. https://doi.org/10.1007/s40641-018-0108-z

Publisher's Note Springer Nature remains neutral with regard to jurisdictional claims in published maps and institutional affiliations. 